\title{
Characteristics of quantifiers moderate the framing effect
}

\section{Dawn L. Holford () | Marie Juanchich 지 | Miroslav Sirota ()}

Department of Psychology, University of Essex, Colchester, UK

\section{Correspondence}

Dawn L. Holford, Department of Psychology, University of Essex, Wivenhoe Park,

Colchester, CO4 3SQ, UK.

Email: dawn.liuholford@gmail.com

Funding information

U.K. Economics and Social Research Council, Grant/Award Number: ES/V011901/1;

Experimental Psychology Society; EssexLab

\begin{abstract}
The attribute framing effect, where people judge a quantity of an item more positively with a positively described attribute (e.g., "75\% lean") than its negative, albeit normatively equivalent description (e.g., " $25 \%$ fat"), is a robust phenomenon, which may be moderated under certain conditions. In this paper, we investigated the moderating effect of the characteristics of the quantifier term: its format (verbal, e.g., "high," or numerical, e.g., "75\%") and magnitude (i.e., if it is a small or large quantity) using positive or negative synonyms of attributes (e.g., energy vs. calories). Over five pre-registered studies using a 2 (synonym, between-subjects: positive or negative) $\times 2$ (quantifier format, between-subjects: verbal or numerical) $\times 2$ (quantifier magnitude, within-subjects: small or large) mixed design, we manipulated quantifier format and magnitude orthogonally for synonyms with differing valence. We also tested two mechanisms for the framing effect: whether the effect was mediated by the affect associated with the frame and whether participants inferred the speaker to be positive about the target. We found a framing effect with synonyms that was reversed in direction for the small (vs. large) quantifiers, but not significantly moderated by quantifier format. Both the affect associated with the frame and the inferred level of speaker positivity partially mediated the framing effect, and the level of mediation varied with quantifier magnitude. These results suggest that the magnitude of the quantifier modifies one's evaluation of the frame, and the mechanism for people's evaluations in a framing situation may differ for small and large quantifiers.
\end{abstract}

\section{KEYWORDS}

affective encoding, attribute framing, framing effect, pragmatic inference, quantifiers, synonym frames

\section{1 | INTRODUCTION}

The attribute framing effect has been a widely studied psychological bias in decision-making since early research demonstrated that people prefer $75 \%$ lean meat to its complementary $25 \%$ fat (Levin, 1987). Extensive research has documented the existence of this framing effect in many important domains (e.g., health care: Gamliel \&
Peer, 2010; medical risks: Peng et al., 2013; Welkenhuysen et al., 2001; business performance: Janiszewski et al., 2003; Kuvaas \& Selart, 2004; sporting performance: Leong et al., 2017; enjoyment of events: Isaac \& Poor, 2016; and even mate choice: Saad \& Gill, 2014). The effect is generally replicable (with an average effect size of $d=0.4$ according to meta-analyses of the effect: Piñon \& Gambara, 2005; Steiger \& Kühberger, 2018). Some conditions have 
been identified that magnify or reduce the effect, which are of research interest because they help understand why framing effects occur (Gal \& Rucker, 2018).

In a typical attribute framing study, participants judge items with an attribute described with one of two complementary phrases, either positive or negative (Levin et al., 1998). The frames are traditionally constructed using complementary proportions of antonyms (e.g., $25 \%$ fat vs. $75 \%$ lean) so that the attribute quantity is the same in each frame, making them logically equivalent. The positive frame is consistently evaluated more favorably than its complementary negative equivalent (Donovan \& Jalleh, 1999; Kim et al., 2014; Levin \& Gaeth, 1988; Seta et al., 2010). Researchers have concluded that the attribute's valence (e.g., fat vs. lean) affects people's judgements and proposed explanations for this effect. The affective encoding account posits that the positively valenced "lean" creates positive affect that leads people to judge the product more favorably compared with the negative affect created by "fat" (Levin \& Gaeth, 1988). Alternatively, the pragmatic inference account posits that speakers choose a positive or negative term to convey some implicit information (Sher \& McKenzie, 2008). People could infer that there is more of the attribute than a reference point (McKenzie \& Nelson, 2003). Listeners can also infer a speaker's viewpoint: for example, the speaker is more positive about the $75 \%$ lean meat as opposed to the $25 \%$ fat meat (Hilton, 2008; Keren, 2007).

The different explanations of the framing effect have found independent empirical support (e.g., Gamliel \& Kreiner, 2019; Sher \& McKenzie, 2006). These explanations focus on how information about the attribute's valence is encoded or interpreted. More recently, researchers also sought to understand how this is affected by the magnitude of the quantifier and how it is represented (Gamliel \& Kreiner, 2019). This paper adds to the limited research on how changing characteristics of the quantifier can produce different perceptions of the overall frame. Specifically, we address how and why a quantifier's format of representation and its magnitude modify the attribute framing effect.

\subsection{Attribute frames consist of attribute and quantifier}

In this paper, we refer to a frame as a sentence that includes a quantity (e.g., a proportion or percentage) of an attribute. The traditional attribute framing paradigm typically considers the quantifier and a positive attribute descriptor as "positive" (e.g., 75\% lean), compared with the other "negative" frame that has a complementary quantifier and negative antonym (e.g., 25\% fat; Levin \& Gaeth, 1988, but see Sher \& McKenzie, 2006, for a valence-neutral construction). Explanations such as the affective encoding account posit that people's judgements are consistent with the valence of the attribute (e.g., positive for $75 \%$ lean and negative for $25 \%$ fat). However, this explanation does not sufficiently take into account the role quantifiers may play in modifying the attributes they are attached to (Kiss \& Pafel, 2017). For instance, one would expect the magnitude of a quantifier to affect the overall valence of the framing sentence and an item that is $5 \%$ fat would be perceived more positively than an item that is $25 \%$ fat.

Several existing studies showed that people identified frames with greater magnitudes of the positive descriptor (e.g., 95\% lean vs. $5 \%$ fat) to be more positive than those with smaller magnitudes of the positive descriptor (e.g., $75 \%$ lean vs. $25 \%$ fat; e.g., Gamliel \& Kreiner, 2019; Liu et al., 2020). In one case, participants even showed a reversal in preference between a $25 \%$ and $5 \%$ positive descriptor (Janiszewski et al., 2003). These findings suggest that the quantity changes the valence of the framing scenario and therefore one's evaluation of it. However, the consequence for the framing effect is less straightforward to determine because complementary quantifiersoften of differing magnitude-are paired with positive and negative antonyms. Some studies found no difference in the framing effect size (i.e., the difference between evaluations of the positive and negative frames; Jin et al., 2017; Kim et al., 2014; Saad \& Gill, 2014): 95\% lean is more positive than $75 \%$ lean, but the complementary $5 \%$ fat is also less negative than $25 \%$ fat. Other studies found that $75 \%$ lean (vs. 25\% fat) displayed a larger framing effect than 95\% lean (vs. 5\% fat; Gamliel \& Kreiner, 2019; Liu et al., 2020; Sanford et al., 2002), which suggests that the magnitude of the quantifier may not affect the valence linearly. Beef that is $95 \%$ lean may be more positive than beef that is $75 \%$ lean, but beef that is $5 \%$ fat could be much less negative than beef that is $25 \%$ fat. Comparing a positive and negative frame with a large and small quantifier may thus not reveal the full effect of the quantifier magnitude.

In addition to variations in magnitude, quantifiers can also exist in different formats: numerical and verbal. Although attribute framing is predominantly studied with numerical quantifiers, some work has shown that framing is also possible with verbal quantifiers (Gamliel \& Kreiner, 2019; Liu et al., 2020; Welkenhuysen et al., 2001; see also Reyna \& Brainerd, 1991, for an example in risky choice framing). Varying quantifier format between numerical and verbal could moderate the effect of frames on people's evaluations. One would expect that verbal quantifiers might produce a larger attribute framing effect than numerical quantifiers for two reasons. First, compared with numerical quantifiers, verbal quantifiers (specifically, verbal probabilities) are believed to be processed more intuitively than numerical ones (Windschitl \& Wells, 1996). For instance, people perceived "1 in 10 chance" to have different event likelihood from the equivalent "10 in 100 chance" when they described it with verbal than numerical quantifiers (Windschitl \& Wells, 1996). Framing effects demonstrate a similar variation in judgment based on information presentation and are argued to be fueled by intuition (Tversky \& Kahneman, 1986). Thus, the effect should be more prevalent when frames use verbal quantifiers. Second, verbal quantifiers place more emphasis on the context than numerical ones (Moxey, 2017), which should increase the effect of the attribute's valence. Of the reported studies on verbal versus numerical quantifiers in attribute framing, one study found that attribute frames with verbal quantifiers produced a framing effect when those with numerical quantifiers did not: participants were more likely to prefer a prenatal test when informed that they had a moderate chance of having a baby with cystic fibrosis (negative frame) than 
a high chance of having a baby without (positive frame); however, they did not show this preference when given a $25 \%$ chance of cystic fibrosis versus $75 \%$ chance of no cystic fibrosis (Welkenhuysen et al., 2001). The other studies did not find evidence that verbal quantifiers (e.g., moderate fat vs. high lean content) magnified the framing effect compared with numerical quantifiers (Gamliel \& Kreiner, 2019; Liu et al., 2020).

A challenge for testing the effect of quantifier format lies in selecting the best pair of verbal quantifiers that will make up complementary frames. Verbal quantifiers do not have precise numerical equivalents. One could select semantic opposites such as high versus low (Gamliel \& Kreiner, 2019), but these may not be how participants would translate the numerical quantifiers. Studies that solicited translations of numerical complements found that people indicated $75 \%$ and $25 \%$ to be "high" and "moderate," respectively (Liu et al., 2020; Welkenhuysen et al., 2001) versus "very high" and "low" for $95 \%$ and $5 \%$ (Liu et al., 2020). From this, one can see that the effect of a verbal versus numerical quantifier could be different for the positive than the negative frame. Comparing different quantifier magnitudes for the positive and negative frame may thus mask some of the effects of quantifier format.

\section{2 | Creating a systematic test of quantifier characteristics}

A direct, systematic test of how the characteristics of a quantifier moderate the framing effect needs to independently manipulate the frame, quantifier magnitude, and quantifier format. Ideally, one would need to compare the same quantifier in the positive frame as the negative to isolate the effect of changing the quantifier characteristics. Such an orthogonal manipulation is not straightforward, ${ }^{1}$ but it is achievable within the broader typology of framing effects. One way to manipulate quantifier characteristics orthogonally to attribute valence is by using synonyms of an attribute that are either positive or negative. This construction is most commonly used in goal framing, which targets whether an individual is persuaded to adopt or support a behavior by framing the same behavior (called a goal) with synonymous descriptors that are either positive or negative (e.g., Epley et al., 2006; Gamliel, 2013; Krishnamurthy et al., 2001; Levin et al., 1998; see also examples in message framing: Dardis \& Shen, 2008). For instance, people were more positive about euthanasia when it was described as "not prolonging life" versus the same, but oppositely valenced "ending life" (Gamliel, 2013).

Goal framing and attribute framing differ on some conceptual and methodological points, although the types can overlap and the typology is not exhaustive (Levin et al., 1998). For example, goal frames target whether one is persuaded by the framing of a behavioral consequence (or goal) as opposed to whether characteristics (attributes) of an item affect one's evaluations of the item in attribute framing (Levin et al., 1998; see also Keren, 2011, for further discussion on framing classifications). Methodologically, attribute frames rely heavily on proportional quantifiers (i.e., percentages) to achieve logical equivalence (i.e., the same amount of the same attribute). In contrast, goal frames can, but does not regularly, invoke quantities of the synonymous descriptions (e.g., describing an equal monetary payout as being "withheld income" vs. "bonus income"; Epley et al., 2006). Attribute frames are also more likely to use antonyms and goal frames synonyms (see Krishnamurthy et al., 2001, for a discussion of why goal framing should use synonyms instead of complementary antonyms to avoid confounds with attribute framing). However, one rare example of synonym use in attribute framing showed that participants were more likely to select the same priced flight framed as including a carbon offset (positive frame) as compared with a carbon tax (negative frame) ${ }^{2}$ (Hardisty et al., 2010). Despite the synonymous attributes referring to the same value and consequence, people still had different attitudes toward them.

As our objective was to investigate the effect of quantifier characteristics, we took the approach of Hardisty et al. (2010) in order to manipulate quantifier characteristics (format and magnitude) orthogonally. To retain the aspects of attribute framing, we manipulated how attributes of a target and assessed participants' evaluations of the targets. We conducted five experiments with three scenarios (food labels: all five experiments; a fish farm and a company: final experiment) to test the framing effect with quantified synonyms, as moderated by quantifier format (i.e., numerical or verbal) and magnitude (e.g., small or large). We also tested whether two mediators-the affect of the frame and how much people inferred a speaker to be positive about a target-would explain the framing effects.

\subsection{Open science statement}

In line with recent scientific guidelines, the methods and analyses for all experiments were pre-registered and can be found on the Open Science Framework along with the materials and data (https://osf.io/ zkmy7/).

\section{$2 \mid$ EXPERIMENT 1}

In Experiment 1, we had two pre-registered hypotheses. ${ }^{3}$ First, people would judge a quantity of the positive synonym of an attribute (energy) as healthier than when it was the same quantity of its negative synonym (calories). Second, the framing effect would be larger for verbal than numerical quantifiers because verbal quantifiers would increase participants' reliance on the affect associated with the attribute.

\section{$2.1 \mid$ Method}

\subsection{1 | Participants}

One hundred and ninety participants (62\% female; $71 \%$ White; ages $18-79$ years, $M=32.51, S D=14.14$ ) were sourced from a university 
lab database. The sample size was determined a priori based on a stopping rule of reaching either the desired sample size $(N=187)$ or by a specific date. We collected three more participants than aimed for due to the recruitment process of the lab. No analyses were performed prior to the completion of data collection. Participants completed the experiment on Qualtrics at the end of an unrelated 20-min medical survey and were compensated with $£ 8$ for the entire study.

\subsection{2 | Design}

Participants made judgements about food in a 2 (synonym, between-subjects: positive or negative) $\times 2$ (quantifier format, between-subjects: verbal or numerical) $\times 3$ (quantifier magnitude, within-subjects: small, moderate, or large) mixed design. Participants also judged the affect of the synonyms (calories or energy) independently from the quantifier.

\subsection{3 | Materials and procedure}

We used the context of food, in which the terms "energy" and "calories" are interchangeably used (e.g., Bleich \& Pollack, 2010; Bucher et al., 2016), but "energy" has more positive connotations than "calories" (Watson et al., 2013).

Participants read the following vignette about a food product that was labelled in one of the framing scenarios shown in Table 1. The quantifier was given in either verbal or numerical format. The attribute was either energy or calories. Participants read the same vignette with the small, medium, and large quantifier described in Table 1, presented

TABLE 1 Orthogonal manipulation of quantifier format and attribute valence to construct frames with synonymous attributes across three quantifier magnitudes in Experiment 1

\begin{tabular}{|c|c|c|}
\hline & Verbal quantifiers & $\begin{array}{l}\text { Numerical } \\
\text { quantifiers }\end{array}$ \\
\hline \multirow[t]{3}{*}{ Positive attributes } & $\begin{array}{r}\text { Provides a low \% of } \\
\text { your daily energy. }\end{array}$ & $\begin{array}{l}\text { Provides } 20 \% \text { of } \\
\text { your daily } \\
\text { energy. }\end{array}$ \\
\hline & $\begin{array}{l}\text { Provides a medium \% } \\
\text { of your daily energy. }\end{array}$ & $\begin{array}{l}\text { Provides } 40 \% \text { of } \\
\text { your daily } \\
\text { energy. }\end{array}$ \\
\hline & $\begin{array}{l}\text { Provides a high \% of } \\
\text { your daily energy. }\end{array}$ & $\begin{array}{l}\text { Provides } 70 \% \text { of } \\
\text { your daily } \\
\text { energy. }\end{array}$ \\
\hline \multirow[t]{3}{*}{ Negative attributes } & $\begin{array}{l}\text { Provides a low } \% \text { of } \\
\text { your daily calories. }\end{array}$ & $\begin{array}{l}\text { Provides } 20 \% \text { of } \\
\text { your daily } \\
\text { calories. }\end{array}$ \\
\hline & $\begin{array}{l}\text { Provides a medium } \% \\
\text { of your daily calories. }\end{array}$ & $\begin{array}{l}\text { Provides } 40 \% \text { of } \\
\text { your daily } \\
\text { calories. }\end{array}$ \\
\hline & $\begin{array}{l}\text { Provides a high \% of } \\
\text { your daily calories. }\end{array}$ & $\begin{array}{l}\text { Provides } 70 \% \text { of } \\
\text { your daily } \\
\text { calories. }\end{array}$ \\
\hline
\end{tabular}

in random order for each participant. Participants rated the healthiness of the food on a 7-point Likert scale (1: very unhealthy, 7: very healthy).

As a measure of affective associations with the attribute, participants next rated the terms "energy" and "calories" individually on a 7-point semantic differential scale with four sets of bipolar adjectives (e.g., bad-good; MacGregor et al., 2000). Participants also judged their affective associations with eight filler nutrients, such as "protein" and "sugar." Scale reliability was excellent, Cronbach's $\alpha=0.95$ (energy) and 0.94 (calories). We calculated the mean for the four adjectives on the scale as a measure of affect, with higher scores indicating a more positive affective association.

Finally, participants reported socio-demographic information, motivation for healthy eating (Naughton et al., 2015), how frequently they used nutrition labels, and their estimated weight and height. On average, participants' BMI was in the slightly overweight category $(M=25.38, S D=7.09)$, and participants had positive attitudes toward healthy eating $(M=5.14, S D=1.02$ on a 7-point scale, with higher scores indicating more positive attitudes). Sixty-seven percent used nutrition labels frequently.

\section{2 | Results}

\subsection{1 | Attribute framing effect}

Participants exhibited a framing effect with the attribute's synonyms, albeit not always in the predicted direction. As shown in Figure 1, participants' judgements of healthiness were more positive for moderate (medium/40\%) and large (high/70\%) energy than for these amounts of calories, $\beta_{\text {moderate-quantifiers }}=0.19, \quad p=.007$, Cohen's $d=0.38$, $\beta_{\text {large-quantifiers }}=0.36, p<.001$, Cohen's $d=0.78$. However, we found unexpectedly that the framing effect reversed in direction with the small quantifiers (low/20\%), with the calorie quantity judged as more healthy than the energy quantity, $\beta_{\text {small-quantifiers }}=-0.20, p=.006$, Cohen's $d=-0.41$.

\subsection{2 | Testing for format moderation of the framing effect}

The difference in magnitude of the framing effect between formats was in the expected direction (greater for verbal than numerical quantifiers), but the moderation was not statistically significant for any of the three quantifier magnitudes, $\beta_{\text {small-quantifiers }}=0.12, p=.083$, $\beta_{\text {moderate-quantifiers }}=0.02, p=.750, \beta_{\text {large-quantifiers }}=-0.03, p=.642$.

\subsubsection{Does affect explain the framing effect?}

We first confirmed that participants had more positive affect for the term "energy" than "calories," assessed independently from their quantifiers $\left(M_{\text {calories }}=4.62, S D=1.51 ; M_{\text {energy }}=6.00, S D=1.04\right)$, $\beta=0.47, \quad p<.001$, Cohen's $d=1.07$. We conducted a planned 
moderated mediation analysis to assess whether the affect associated with the attribute predicted variations in the magnitude of the framing effect for each of the quantifier magnitudes. This is a conditional process model (illustrated in Figure 2) using the PROCESS macro in SPSS (Model 15, using bias-corrected bootstrap confidence intervals with 5000 samples; Hayes, 2013) ${ }^{4}$ to estimate the framing effect on healthiness judgment (direct effect), as mediated by affect (indirect effect) and moderated by format. All variables were mean-centered prior to analysis.

The path labelled $b$ in Figure 2 illustrates the effect of affect on healthiness judgment. Affect predicted healthiness with small and large quantifiers, but not moderate ones, $\beta_{\text {small-quantities }}=-0.28$, $p<.001, \quad \beta_{\text {moderate-quantities }}=0.12, \quad p=.133, \quad \beta_{\text {large-quantities }}=0.24$, $p=.001$. This was not significantly moderated by format (all $p s>.05$, reported in the appendix, Table A1).

The path labelled $c^{\prime}$ in Figure 2 illustrates the direct framing effect on healthiness judgment, after controlling for affect. The direct framing effect on healthiness judgements was significant for large quantifiers only, $\beta_{\text {small-quantifiers }}=-0.07, p=.392, \beta_{\text {moderate-quantifiers }}=0.13$, $p=.096, \beta_{\text {large-quantifiers }}=0.26, p<.001$. This direct effect was not moderated by format (all ps $>.05$, reported in the appendix, Table A1).

The indirect effect, assessing whether affect mediated the framing effect on healthiness, showed different findings across quantifier magnitudes. We found a significant mediation effect with small quantifiers for both formats, $b_{\text {verbal }}=-0.27,95 \% \mathrm{Cl}[-0.54,-0.02]$, $b_{\text {numerical }}=-0.25,95 \% \mathrm{Cl}[-0.49,-0.05]$. However, the mediation was not significant for moderate quantifiers, $b_{\text {verbal }}=0.12,95 \% \mathrm{Cl}$ $[-0.07,0.34], b_{\text {numerical }}=0.10,95 \% \mathrm{Cl}[-0.11,0.32]$. Finally, for large quantifiers, affect significantly mediated the framing effect for verbal, but not numerical quantifiers, $b_{\text {verbal }}=0.32,95 \% \mathrm{Cl}[0.13,0.55]$, $b_{\text {numerical }}=0.14,95 \% \mathrm{Cl}[-0.04,0.32]$.

\section{3 | Discussion}

In Experiment 1, we found that participants associated "energy" with significantly more positive affect than "calories," which suggested that these synonyms have differing valence. Using these synonyms, we tested whether quantifier format would moderate the attribute

FIGURE 1 Effects of attribute (green circles vs. red squares) and format ( $x$-axis) on healthiness judgements across three quantifier magnitudes in Experiment 1. Error bars reflect 95\% confidence intervals. The difference between the green circles and red squares shows the magnitude and direction of the framing effect in each condition [Colour figure can be viewed at wileyonlinelibrary. com]

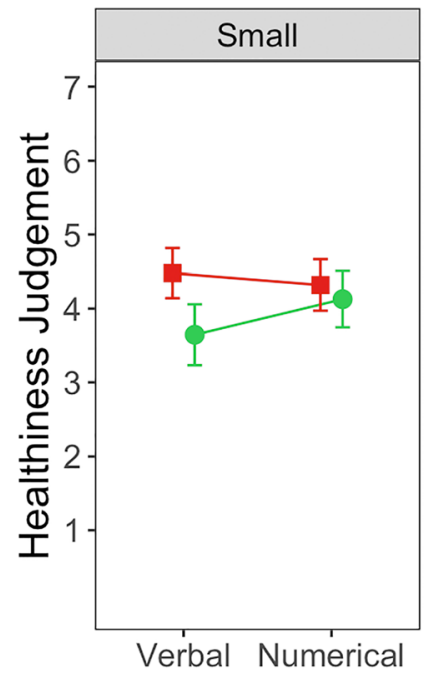

\section{Affective encoding model}

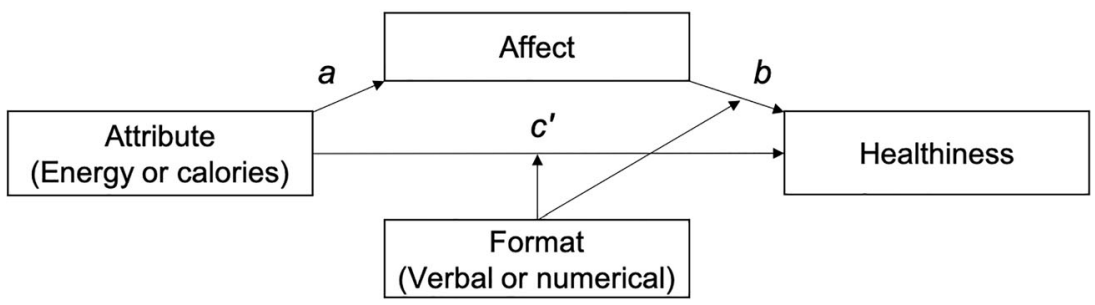

FIGURE 2 Moderated mediation model used in Experiments 1 and 2a, testing whether affect mediates the effect of the attribute on healthiness judgment, as moderated by format. The letters $a, b$, and $c^{\prime}$ indicated the regression coefficients for the individual pathways in the model. Binary variables were dummy coded (calories $=0$, numerical $=0$ ). The hypothesis testing coefficients are presented in the text and the full model coefficients are provided in the appendix (Tables A1 and A2) 
framing effect, as explained by the greater role of affect when quantifiers were verbal. We did not find the expected moderation by quantifier format, and the role of affect was complex: affect significantly mediated the framing effect for verbal and not numerical quantifiers only when they were large. Interestingly and unexpectedly, the effect for small quantifiers was opposite in direction from large quantifiers: people judged low calories (negative attribute) as healthier than low energy (positive attribute). In the next set of experiments, we sought to test the effects of quantifier format and magnitude further and investigate two mediators of the framing effect.

\section{3 | EXPERIMENTS $2 a-2 b$}

The goal of the next two experiments was to test again the role of quantifier format as a moderator of the attribute framing effect at different magnitude levels of the quantifier. Additionally, we tested in separate experiments two explanatory variables as mediators of the framing effect: affect (Experiment 2a) and whether participants inferred the speaker to be positive about the food (Experiment 2b). We hypothesized that for large quantifiers, the energy quantity would be judged healthier than the calorie one, but for small quantifiers, the calorie quantity would be judged healthier than the energy one ( $2 a$ and $2 b$ ). We also hypothesized that verbal quantifier would produce a large framing effect because compared with numerical quantifiers, they would increase participants' reliance on the affect associated with the attribute (2a) and participants would more likely infer speaker positivity for verbal quantifiers $(2 \mathrm{~b})$. $^{5}$

In these experiments, we implemented an improved design to address a limitation of Experiment 1, where we had used verbal and numerical percentages for energy that are on average psychologically equivalent (Liu et al., 2019). Individual participants may have perceived the verbal quantifiers differently (e.g., one might believe low calories to be less than 20\%), which would make the frames inequivalent between formats. To control for this individual variability, we had participants first translate the verbal percentages of energy or calories into a numerical percentage. These translations were later used to solicit participants' healthiness judgements in the numerical condition. We first describe the general method across the experiments, and then results for each experiment.

\section{1 | Method}

\subsection{1 | Participants}

In Experiment 2a, participants were sourced from a survey panel ( $N=194$, rewarded with online vouchers) and undergraduate participant pool ( $N=141$, rewarded with course credit). The experiment was powered to detect an attribute $\times$ quantifier format interaction based on the effect size observed in Experiment 1 ( $f=0.10, \alpha=.05$, $1-\beta=.80$ ). We checked before combining the samples that the two samples did not differ significantly in their response to the manipulations. Participants were $59 \%$ female, $80 \%$ White, and aged 1876 years $(M=37.76, S D=17.30)$. Their mean $B M I$ was healthy $(M=24.99, S D=5.78)$. Participants' had slightly positive attitudes toward healthy eating $(M=4.89, S D=0.98)$ and $53 \%$ used nutrition labels frequently.

In Experiment 2b, we sourced participants through a university sample ( $N=71$, voluntary participation) and a survey panel $(N=223$, paid £0.70). We powered the sample to detect a synonym $\times$ quantifier format interaction with effect size $f=0.10$, $\alpha=.05,1-\beta=.80$. We checked before combining the samples that the two samples did not differ significantly in their response to the manipulations. Participants were $69 \%$ female, $88 \%$ White, aged $18-$ 71 years $(M=37.38, S D=13.24)$. Participants' $B M I$ was on average in the overweight category $(M=27.03, S D=7.18)$. They had slightly positive attitudes to healthy eating $(M=4.84, S D=0.95)$, and $71 \%$ used nutrition labels frequently.

\subsection{2 | Design}

In both experiments, participants gave healthiness judgements in a 2 (synonym, between-subjects: energy or calories) $\times 2$ (quantifier format, between-subjects: verbal or numerical) $\times 2$ (quantifier magnitude, within-subjects: small or large) mixed design. Compared with Experiment 1, we manipulated only small and large quantifiers (not moderate) because moderate quantifiers had a similar pattern of results to large quantifiers in Experiment 1.

In Experiment 2a, participants made affect judgements for either energy or calories (independently of the quantifier). In Experiment $2 b$, participants inferred a speaker's positivity from each framed sentence (including both quantifier and attribute) using the same mixed design as for the healthiness judgements.

\subsection{3 | Materials and procedure}

In both experiments, participants first provided numerical percentages for a low $\%$ and high \% of either calories or energy. ${ }^{6}$ These translations were used as the within-subject quantifier magnitudes in the numerical condition. As part of the translation task, participants also provided filler translations of other quantifiers (e.g., translating $25 \%$ fat into a verbal equivalent) to avoid our research design being transparent to participants.

To distract participants from focusing on the translations they had provided, participants next completed a filler task similar to one used in Teigen et al. (2014). After this, participants completed the healthiness judgment task from Experiment 1 for the small and large quantifiers (verbal or numerical). For Experiment 2a, we also asked participants how much they would be willing to pay for a cereal bar with that energy (or calorie) description. ${ }^{7}$

Participants also completed a measure of the mediator variables of interest. In Experiment 2a, this was the affect associated with the 
attribute (energy or calories), measured on a 7-point semantic differential scale identical to Experiment 1 (scale reliability was excellent, Cronbach's $\alpha_{\text {energy }}=0.90$; Cronbach's $\alpha_{\text {calories }}=0.90$ ). In Experiment $2 \mathrm{~b}$, the mediator variable tested was an inferred speaker's level of positivity. Participants rated how much they agreed with three statements about how positive the speaker felt about the food product: that the participant should buy the food, that the food was healthy, and that the product was good. Participants rated the statements on a 7-point Likert scale (1: strongly disagree, 7: strongly agree). Scale reliability was good, Cronbach's $\alpha=0.89$ (small quantifiers) and 0.86 (large quantifiers). We computed an inferred speaker positivity rating from the average of the measures.
Finally, participants provided the same socio-demographic information and measures collected in Experiment 1.

\section{2 | Results}

\subsection{1 | Experiment 2a}

Attribute framing effects and moderation by quantifier format

We found framing effects on healthiness judgements that were opposite in direction for small and large quantifiers, as shown in the top panel of Figure 3. Participants judged large quantities of energy more

\section{Experiment 2a}
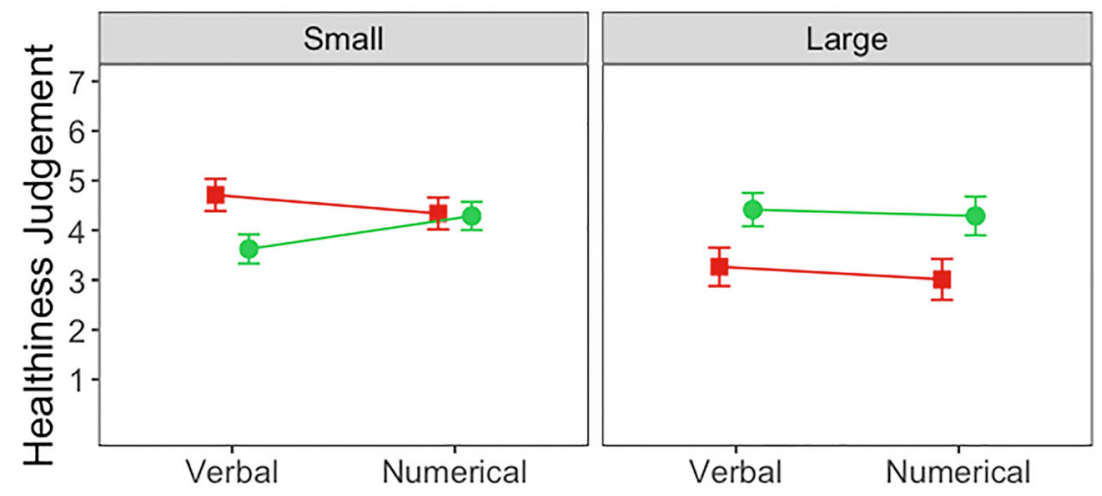

Experiment $2 \mathrm{~b}$

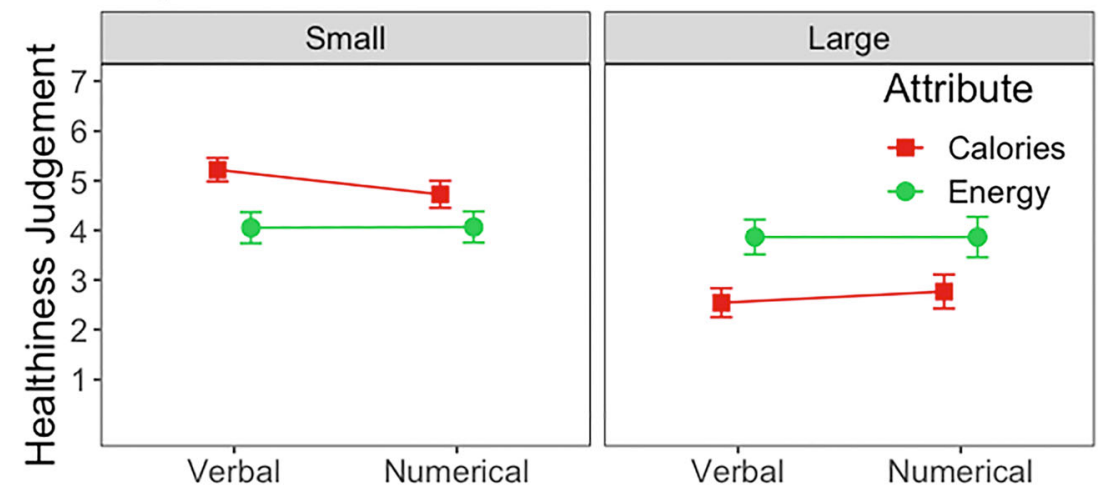

Experiment 3

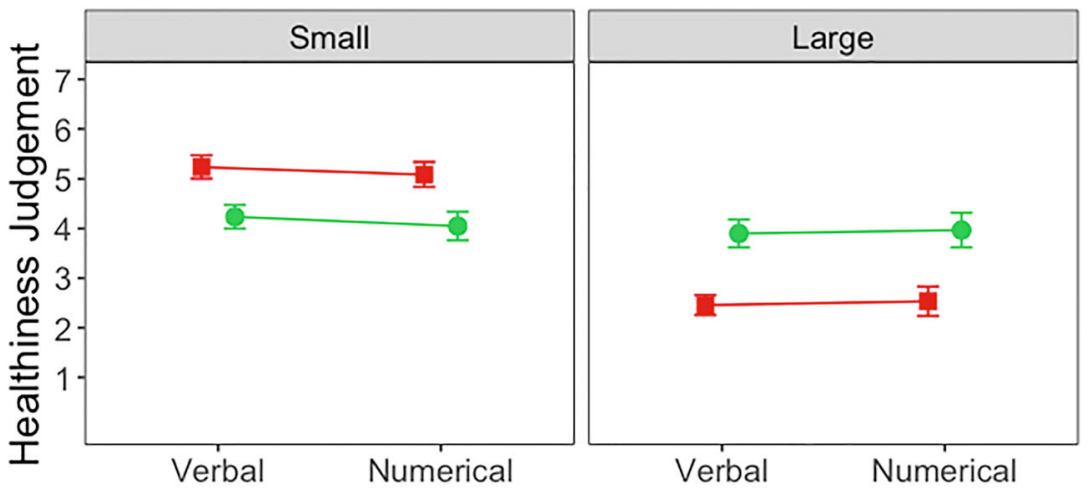

Verbal Numerical

Verbal Numerical
FIGURE 3 Effects of the attribute (green circles vs. red squares) and quantifier format ( $x$ axis) on healthiness judgements for small and large quantifiers in Experiments 2a (top panel), 2b (middle panel), and 3 (bottom panel). Error bars reflect $95 \%$ confidence intervals. The difference between the green circles and red squares shows the size and direction of the framing effect in each condition [Colour figure can be viewed at wileyonlinelibrary.com] 
positively than calories, $\beta=0.31, p<.001$, Cohen's $d=0.69$. However, the direction of the effect was reversed for small quantifiers, with calories more healthy than energy, $\beta=-0.37, p<.001$, Cohen's $d=-0.39$. Quantifier format moderated the framing effect only for small quantifiers: the framing effect was found for verbal but not numerical quantifiers, $\beta=0.31, p<.001$. However, quantifier format did not moderate the framing effect for large quantifiers, $\beta=0.03, p=.743$.

\section{Does affect explain the framing effect?}

Participants had more positive affect for "energy" than "calories," each assessed independently $\left(M_{\text {calories }}=4.12, S D=1.46, \quad M_{\text {en- }}\right.$ ergy $=5.61, S D=1.22), \beta=0.49, p<.001$, Cohen's $d=1.11$. Using the same moderated mediation analysis as Experiment 1, we found that affect predicted healthiness for large but not small quantifiers, $\beta_{\text {small-quantifiers }}=-0.12, \quad p=.143, \quad \beta_{\text {large-quantifiers }}=0.39, \quad p<.001$. After accounting for affect, there remained a significant direct framing effect on healthiness judgements, $\beta_{\text {small-quantifiers }}=-0.31, p<.001$, $\beta_{\text {large-quantifiers }}=0.16, p=.042$. This effect was greater for verbal than numerical formats in the small, but not large, quantifiers, $\beta_{\text {small-qua- }}$ ntifiers $=0.29, p=.008, \beta_{\text {large-quantifiers }}=0.01, p=.898$. The conditional indirect effect, testing the mediation by affect of the framing effect on healthiness, showed no significant mediation for small quantifiers, $b_{\text {verbal }}=-0.12,95 \% \mathrm{Cl}[-0.31,0.06], b_{\text {numerical }}=-0.06,95 \%$ $\mathrm{Cl}[-0.30,0.15]$. In contrast, there was a significant mediation by affect for large quantifiers, $b_{\text {verbal }}=0.31,95 \% \mathrm{Cl}[0.15,0.48]$, $b_{\text {numerical }}=0.32,95 \% \mathrm{Cl}[0.15,0.53]$.

\subsection{2 | Experiment $2 \mathrm{~b}$}

\section{Attribute framing effects and moderation by format}

As shown in the middle panel of Figure 3, we replicated the framing effect on healthiness judgements. Participants judged that large quantities of energy were healthier than the equivalent quantity in calories, $\beta=0.37, p<.001$, Cohen's $d=0.80$. Small quantifiers reversed the direction of the effect, with participants judging that calorie quantities were healthier than energy quantities, $\beta=-0.35, \quad p<.001$, Cohen's $d=-0.74$. However, we did not find the predicted moderation by quantifier format, $\beta_{\text {small-quantifiers }}=0.10, p=.078$, $\beta_{\text {large-quantifiers }}=-0.04, p=.520$.

\section{Does inferred speaker positivity explain the framing effect?}

We assessed participants inferences about speaker positivity for the full quantified sentence (including the quantifier). These inferences matched the framing effect on healthiness judgements: participants inferred more speaker positivity for large quantities of energy versus calories, and small quantities of calories versus energy, $\beta_{\text {small-qua- }}$ ntifiers $=0.34, p<.001 ; \beta_{\text {large-quantifiers }}=-0.34, p<.001$. Using the PROCESS macro in SPSS (Model 8; (Hayes, 2013), we conducted a planned moderated mediation analysis (illustrated in Figure 4) to assess whether inferences about the speaker's positivity predicted the framing effect for the two quantifier magnitudes. Because participants drew these inferences from the full frame (attribute and quantifier), we assessed this mediator for the entire quantified phrase (e.g., "low calories") instead of for the independent attribute (e.g., "calories"). Therefore, we expected quantifier format to moderate the $a$ path instead of the $b$ path in Figure 4 .

Inferred speaker positivity significantly predicted healthiness judgements for both quantifier magnitudes, $\beta_{\text {small-quantifiers }}=0.58$, $p<.001 ; \beta_{\text {large-quantifiers }}=0.59, p<.001$ (path $b$ in Figure 4). After accounting for the inferred speaker positivity, there remained a significant direct framing effect on healthiness judgements, $\beta_{\text {small- }}$ quantifiers $=-0.19, p=.005, \beta_{\text {large-quantifiers }}=0.16, p=.016$. Quantifier format did not moderate the direct effects, $\beta_{\text {small-quantifiers }}=0.07$, $p=.389, \beta_{\text {large-quantifiers }}=0.02, p=.748$. The conditional indirect effect, testing the mediation by inferred speaker positivity of the framing effect, showed a significant mediation for small quantifiers, $b_{\text {verbal }}=-0.51,95 \% \mathrm{Cl}[-0.70,-0.33], b_{\text {numerical }}=-0.28,95 \% \mathrm{Cl}$ $[-0.47,-0.10]$; and large quantifiers: $b_{\text {verbal }}=0.50,95 \% \mathrm{Cl}[0.32$, $0.70], b_{\text {numerical }}=0.31,95 \% \mathrm{Cl}[0.10,0.52]$.

\section{3 | Discussion}

Our second set of experiments found mixed support for our prediction that quantifier format would moderate the framing effect. Only for

\section{Pragmatic inference model}

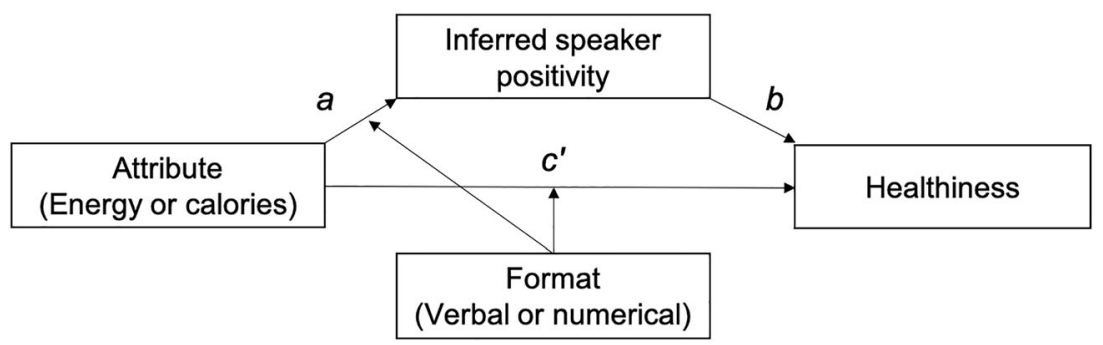

FIGURE 4 Moderated mediation model used in Experiment $2 b$, testing whether inferred speaker positivity mediates the effect of attribute on healthiness judgements, as moderated by quantifier format. The letters $a, b$, and $c^{\prime}$ indicate the regression coefficients for the individual pathways in the model. Binary variables were dummy coded (calories $=0$, numerical $=0$ ). The hypothesis testing coefficients are presented in the text and the full model coefficients are provided in the appendix (Table A3) 
small quantifiers in Experiment 2a did we find a framing effect for verbal but not numerical quantifiers (in line with Welkenhuysen et al., 2001). In contrast, there was a consistent framing effect for large quantifiers, whether verbal or numerical. Critically, the direction of the framing effect was consistent with the affect associated with the attribute for large quantifiers, but reversed from the attribute's affect for small quantifiers. In addition, the mediation analyses showed that affect mediated the framing effect for large, but not small, quantifiers, while inferred speaker positivity mediated the framing effect for both quantifier magnitudes. However, the mediation analyses differed because Experiment $2 \mathrm{a}$ tested the affect associated with the attribute separately from the quantifier (e.g., "energy") while Experiment $2 b$ tested the inferred speaker positivity from the full frame (e.g., "low \% energy"). Given that the framing effect was in the opposite direction to the attribute's affect for small quantifiers, it is possible that the quantifier also modified the affect of the attribute, which was not captured by our measure. We sought to address this in Experiment 3 by measuring participants' affective associations with the full quantified phrase (i.e., "low \% energy" as opposed to simply "energy").

\section{4 | EXPERIMENT 3}

In Experiment 3, we sought to replicate the framing effect with the synonyms energy and calories, expecting that large energy quantities would be judged healthier than large calorie quantities, and vice versa for the frames with small quantifiers. We also hypothesized that the framing effects for each quantifier magnitude would be mediated by both affect and inferences about speaker positivity. We also tested again the hypothesis that verbal quantifiers would produce larger framing effect than numerical quantifiers. ${ }^{8}$

\section{1 | Method}

\subsection{1 | Participants}

The experiment was powered to detect the smallest mediation effect size obtained in the previous experiments (a path $=0.49$, $b$ path $=0.16$, target $N=391$; Fritz \& MacKinnon, 2007). We collected 17 additional responses due to a delay in closing the survey. Four hundred and eight participants (68\% female, $28 \%$ male, $4 \%$ undisclosed; $86 \%$ White, aged $18-85$ years, $M=35.54, S D=12.12$ ) completed the experiment on Prolific Academic for $£ 0.70$. Participants' average BMI was in the overweight category $(M=26.94, S D=7.73)$ and they had slightly positive attitudes toward healthy eating $(M=4.91, S D=0.99)$. Seventy-three percent used nutrition labels frequently.

\subsection{2 | Design}

We used a 2 (synonym: energy or calories, between-subjects) $\times 2$ (quantifier format: verbal or numerical, between-subjects) $\times 2$ (quantifier magnitude: small and large, within-subjects) mixed design for all measures (healthiness judgment, affect, and inferred speaker positivity). In contrast with the previous experiments, this design allowed us to capture how the quantifier magnitude modified the affect for an attribute.

\subsection{3 | Materials and procedure}

As in Experiments 2a and 2b, participants provided numerical translations of verbal quantifiers, ${ }^{9}$ followed by a filler task. Participants then completed in random order: the healthiness judgment task (same as previous experiments), the inferred speaker positivity scale (same as Experiment $2 b$; Cronbach's $\alpha_{\text {small-quantifiers }}=0.90$ and $\alpha_{\text {large-qua- }}$ ntifiers $=0.87$ ), and the semantic differential scale for small and large quantities (verbal or numerical, depending on condition) of either energy or calories (Cronbach's $\alpha_{\text {small-quantifiers }}=0.90, \alpha_{\text {large-qua- }}$ ntifiers $=0.87$ ). Participants completed this set of three tasks twice each: once for the small and once for the large quantifier, in randomized order. Finally, socio-demographic measures were collected.

\section{2 | Results}

\subsection{1 | Attribute framing effects and moderation by format}

We found the expected framing effects on healthiness judgements, illustrated in the bottom panel of Figure 3. The effect was in opposite directions for the two quantifier magnitudes, $\beta_{\text {small-quantifiers }}=-0.37$, $p<.001$, Cohen's $d=-0.8, \beta_{\text {large-quantifiers }}=0.45, p<.001$, Cohen's $d=1.00$. However, we did not find the predicted moderating effects of quantifier format, $\beta_{\text {small-quantifiers }}=-0.01, \quad p=.886, \quad \beta_{\text {large- }}$ quantifiers $=-0.001, p=.977$.

\subsection{2 | Reversal of attribute framing effect between small and large quantifiers}

We conducted a planned moderation analysis to formally test for the effect of quantifier magnitude on the framing effect with healthiness judgements. As expected, there was a significant interaction between attribute and quantifier magnitude. Participants judged large quantities of energy more positively than calories, but they judged small quantities of calories more positively than energy, $\beta=0.52, p<.001$.

\subsubsection{How much do affect and inferred speaker positivity explain the framing effect?}

The synonym and quantifier in the frame affected participants' levels of affect and inferred speaker positivity. Large quantities of energy elicited more positive affect and speaker positivity than large quantities 
of calories, and vice versa, $\beta_{\text {small-quantifiers }}=-0.34, p<.001, \beta_{\text {large-qua- }}$ ntifiers $=0.44, p<.001 ;$ speaker positivity: $\beta_{\text {small-quantifiers }}=-0.37$, $p<.001, \beta_{\text {large-quantifiers }}=0.41, p<.001$. We conducted a parallel mediation model testing affect and inferred speaker positivity as mediators of the framing effect on healthiness judgements using PROCESS for SPSS (Model 4, illustrated in Figure 5; Hayes, 2013). ${ }^{10}$ The model did not include quantifier format as a moderator since the hypothesis that format would moderate the framing effect on healthiness judgements was not supported. We opted for parallel mediators because the existing theoretical accounts for the explanatory mechanisms of interest had not specified an interactive role between mediators.

Affect and inferred speaker positivity both significantly predicted healthiness judgements (the $b$ paths in Figure 5), affect: $\beta_{\text {small-qua- }}$ ${ }_{\text {ntifiers }}=0.45, p<.001, \beta_{\text {large-quantifiers }}=0.54, p<.001$; speaker positivity: $\beta_{\text {small-quantifiers }}=0.30, p<.001, \beta_{\text {large-quantifiers }}=0.29, p<.001$. After accounting for affect and inferred speaker positivity, there was still a significant, though reduced, direct framing effect on healthiness judgements, $\beta_{\text {small-quantifiers }}=-0.10, p=.005, \beta_{\text {large-quantifiers }}=0.09$, $p=.010$. The indirect effects showed a significant mediation of the framing effect on healthiness judgment, $b_{\text {small-quantifiers }}=-0.53,95 \%$ $\mathrm{Cl}[-0.42,-0.21], b_{\text {large-quantifiers }}=0.72,95 \% \mathrm{Cl}[0.58,0.85]$. Affect accounted for more of the mediation effects than inferred speaker positivity (double, in the case of large quantifiers), affect: $b_{\text {small- }}$ quantifiers $=-0.31,95 \% \mathrm{Cl}[-0.42,-0.20], b_{\text {large-quantifiers }}=0.49,95 \%$ $\mathrm{Cl}[0.35,0.62]$; speaker positivity: $b_{\text {small-quantifiers }}=-0.22,95 \% \mathrm{Cl}$ $[-0.32,-0.14], b_{\text {large-quantifiers }}=0.24,95 \% \mathrm{Cl}[0.15,0.33]$.

\section{3 | Discussion}

Across our experiments thus far, we produced a framing effect with frames using the same quantity of two synonyms with different valence, but the direction of the effect was determined by the quantifier magnitude: large quantities of the positive synonym were judged more positively than that of the negative synonym (as expected with a framing effect), but small quantities of the negative synonym were judged more positively than small quantities of the positive synonym. Regarding the role of format, Experiment 3 did not find that quantifier format significantly moderated the framing effect on healthiness judgment. This was in line with Experiments 1 and $2 b$ but in contrast with Experiment $2 \mathrm{a}$.

The use of synonyms was necessary to evaluate whether the characteristics of quantifiers moderate the effect of framing, as we could isolate effects for small versus large and verbal versus numerical quantifiers. However, our investigation thus far only focused on one set of synonyms (energy vs. calories). We thus sought to replicate and extend our findings from the food scenario to other synonyms in the next experiment.

\section{\begin{tabular}{l|l}
5 & EXPERIMENT 4
\end{tabular}}

The goal of Experiment 4 was to test whether the framing effects as moderated by quantifier magnitude and the explanatory variables of affect and inferred speaker positivity would generalize to other synonyms. To do so, we tested the framing effect for the original energy versus calories pair as well as two different synonym pairs: utilized versus depleted and dismissed versus fired. We pre-tested the synonym pairs among 107 participants to check that they produced a perceived valence difference of at least a medium size (i.e., Cohen's $d=0.50$ ).

We hypothesized that the quantifier magnitude would moderate a framing effect between an attribute's positive and negative synonyms, with large quantities of positive synonyms judged more positively than the same negative synonyms, but small quantities of negative synonyms judged more positively than the same positive synonyms. Assuming the framing effects held, we planned to test if verbal quantifiers would have a larger framing effect than numerical ones, and if the framing effect would be mediated by participants' level of affect and inferred speaker positivity. ${ }^{11}$

\section{$5.1 \mid$ Method}

\subsection{1 | Participants}

We collected and stopped data collection once we had 408 participants (targeted to match the sample of Experiment 3). Participants were

\section{Parallel mediation model}

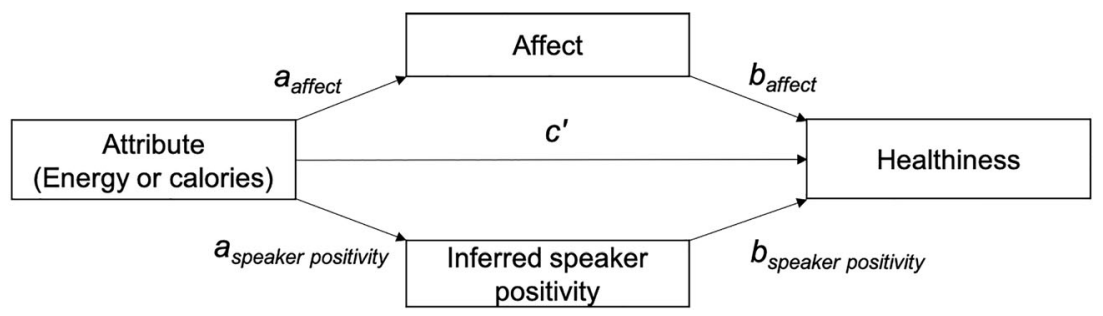

FIGURE 5 Parallel mediation model testing whether affect and inferred speaker positivity mediate the effect of the attribute on healthiness judgment. The letters $a, b$, and $c^{\prime}$ indicate the regression coefficients for the respective pathways in the model. Binary variables were dummy coded (calories $=0$ ). The hypothesis testing coefficients are presented in the text and the full model coefficients are provided in the appendix (Table A4). Note: We tested this model for each quantifier magnitude (small and large) in Experiment 3. In Experiment 4, we added quantifier magnitude as a moderator of the $a$ and $c^{\prime}$ paths in this model 
150 psychology undergraduate students, who received course credits, and 258 respondents from Prolific Academic, who received $£ 1$ for participation. Before combining the samples for analysis, we confirmed that the two samples did not differ significantly in their response to the manipulations. Participants were aged $18-71$ years $(M=29.05$, $S D=10.74), 70 \%$ female, and $74 \%$ White. Following our pre-registered criterion, we excluded from analyses involving quantifier magnitude cases where participants perceived the two numerical quantifiers to be verbally equivalent, as there would be no difference in the small and large quantifiers for these cases. This resulted in 7 (1.7\%) exclusions for the food scenario, 17 (4.2\%) for the fish farm scenario, and 24 (5.9\%) for the business scenario. A robustness check of the same analyses including these cases did not change the nature of our results.

\subsection{2 | Design}

We used the 2 (synonym: positive or negative, between-subjects) $\times 2$ (quantifier format: verbal or numerical, between-subjects) $\times 2$ (quantifier magnitude, small and large, within-subjects) design of Experiment 3 , repeated across three framing scenarios (see Table 2).

\subsection{3 | Materials}

Prior to the experiment, we pre-tested three synonym pairs with 107 participants to assess the difference in their valence: energy versus calories, utilized versus depleted, and dismissed versus fired. Materials and results for this pre-test are summarized in Table 2, with a full report available as supporting information. All the synonym pairs produced a significant valence difference of $d>0.50 .{ }^{12}$

\section{\begin{tabular}{l|l} 
5.1.4 & Procedure
\end{tabular}}

Participants first completed a translation task, followed by a 3- to 5-min distractor task, and then the following tasks presented in random order to each participant: a favorability judgment task, an affective judgment task, and an inferred speaker positivity task. Finally, participants provided socio-demographic information.

\section{Translation task}

To extend our findings to numerical-verbal translations, we reversed the translation task in the previous experiments such that participants provided verbal quantifiers that best expressed the numerical quantifiers of the framed attribute. For example, participants selected which of the verbal quantifiers, low, moderate, or high, best described " $15 \%$ energy" (positive small condition) or " $65 \%$ energy" (positive large condition). We used $15 \%$ and $65 \%$ because these were average translations of low $\%$ and high $\%$ found in the previous four experiments reported here. Participants provided translations for $15 \%$ and $65 \%$ for all three of the framing scenarios (described in Table 2). Each participants' translations were subsequently used to construct the frames in the verbal quantifier condition.

\section{Framing effect measure: Attitude favorability task}

We assessed the framing effect by asking participants to rate their attitude toward the described target (the food, the fish farm, or the business) on a 7-point Likert scale (1: not at all favorable, 7: very favorable). This measure maintained a constant value judgment across the three scenarios and allowed us to test whether the framing effects observed in Experiments 1-3 would extend to a different type of judgment.

\section{Mediator variable measure: Affect association task}

For each scenario (featuring both attribute and quantifier), participants completed a semantic differential scale with four bipolar adjective anchors as in Experiment 3. Scale reliability was excellent for all scenarios and quantifiers, Cronbach's $\alpha \geq 0.91$. We calculated the mean of the four items as each participant's level of affect associated with the frame.

\section{Mediator variable measure: Inferred speaker positivity task}

For each scenario, participants inferred whether the speaker was positive about the target by rating their level of agreement with three statements reflecting the speaker's positive attitude (as in Experiments $2 b$ and 3; for example: "The speaker believes the fish farm's practices are good"). Scale reliability was good for all scenarios and quantifiers, Cronbach's $\alpha \geq 0.89$. We calculated the mean of the three items for each participant, with a higher mean score meaning greater agreement that the speaker was positive toward the target.

TAB LE 2 Positive and negative synonymous attributes used in three framing scenarios

\begin{tabular}{|c|c|c|c|c|}
\hline Scenario & $\begin{array}{l}\text { Positive } \\
\text { frame }\end{array}$ & $\begin{array}{l}\text { Negative } \\
\text { frame }\end{array}$ & $\begin{array}{l}\text { Pre-tested valence effect } \\
\text { size }(d)\end{array}$ & Example scenario \\
\hline Label on food product. & Energy & Calories & $1.54^{* * *}$ & This food provides $15 \%$ of your daily calories. \\
\hline Fish stocks at a fish farm. & Utilized & Depleted & $1.70^{* * *}$ & $\begin{array}{l}\text { The farm has depleted } 15 \% \text { of its annual fish } \\
\text { stocks. }\end{array}$ \\
\hline $\begin{array}{l}\text { Business undergoing } \\
\text { restructuring. }\end{array}$ & Dismissed & Fired & $0.63^{* *}$ & The company fired $15 \%$ of its employees. \\
\hline
\end{tabular}

Note: The quantifier was either small or large (e.g., $15 \%$ vs. $65 \%$ ) and verbal or numerical (e.g., a low \% vs. $15 \%$ ).

${ }^{* *} p<.01 .{ }^{* * *} p<.001$. 


\section{2 | Results}

We tested for three hypotheses. First, we expected a framing effect on participants' attitudes about the scenarios that was larger in the verbal than the numerical condition. Second, we expected the framing effect would be opposite in direction for the small versus large quantifiers. Third, we expected that affect and inferred speaker positivity would mediate the framing effect.

\subsection{1 | Attribute framing effect and moderation by quantifier characteristics}

We found that the synonym significantly affected participants' attitudes, moderated by the quantifier magnitude, in two out of three scenarios (food and fish farm, but not business), as illustrated in Figure $6, \quad \beta_{\text {food }}=0.36, \quad p<.001, \quad \beta_{\text {fish-farm }}=0.35, \quad p<.001$, $\beta_{\text {business }}=-0.04, p=.190$. Participants had more favorable attitudes toward large quantities of energy and utilized fish stocks versus the equivalent but more negative calories and depleted fish stocks, $\beta_{\text {large- }}$ food-quantities $=0.41, \quad p<.001, \quad$ Cohen's $\quad d=0.89, \quad \beta_{\text {large-fish- }}$ quantities $=0.51, p<.001$, Cohen's $d=1.17$. Conversely, they had more favorable attitudes toward small quantities of calories and depleted fish stocks versus the equivalent but more positive energy and utilized fish stocks, $\beta_{\text {small-food-quantities }}=-0.31, p<.001$, Cohen's $d=-0.63, \beta_{\text {small-fish-quantities }}=-0.18, p<.001$, Cohen's $d=-0.37$. In the business scenario, we did not observe the hypothesized framing effect for the quantities of employees dismissed versus fired, $\beta_{\text {small- }}$ employee-quantities $=-0.08, p=.095$, Cohen's $d=0.15, \beta_{\text {large-employee- }}$ quantities $=-0.01, p<.812$, Cohen's $d=-0.04$. We do not report further analyses on the business scenario.

Regarding the quantifier format, the moderating effect was inconsistent. Quantifier format significantly moderated the framing effect on favorability judgements for large quantifiers in the food and fish farm scenarios, but unexpectedly, it was the numerical quantifiers that exhibited the bigger framing effect compared with the verbal quantifiers, $\quad \beta_{\text {large-food-quantities }}=0.10, \quad p=.029, \quad \beta_{\text {large-fish-quantities }}=0.10$, $p=.023$. There was no significant moderation by quantifier format for small quantifiers, $\beta_{\text {small-food-quantities }}=-0.001, p=.989, \beta_{\text {small-fish- }}$ quantities $=-0.06, p=.232$

\subsection{2 | How much do affect and inferred speaker positivity explain the framing effect?}

Similar to their attitudes, participants' levels of affect and inferred speaker positivity were more positive for large quantities of positive than negative synonyms, affect: $\beta_{\text {large-food-quantities }}=0.42, p<.001$, $\beta_{\text {large-fish-quantities }}=0.54 \quad p<.001 ; \quad$ speaker positivity: $\beta_{\text {large-food- }}$ quantities $=0.41, \quad p<.001, \quad \beta_{\text {large-fish-quantities }}=0.49, \quad p<.001$. Conversely, these measures were less positive for small quantities of negative than positive synonyms, affect: $\beta_{\text {small-food-quantities }}=-0.16$, $p<.001, \quad \beta_{\text {small-fish-quantities }}=-0.10, \quad p=.039$, speaker positivity: $\beta_{\text {small-food-quantities }}=-0.22, \quad p<.001, \quad \beta_{\text {small-fish-quantities }}=-0.17$, $p<.001$.

We performed planned moderated mediation analyses on participants' attitudes in the food and fish farm scenarios, using the model illustrated in Figure 5, to which we added quantifier magnitude as a moderator of the framing effects on judgements, affect, and inferred speaker positivity ( $c^{\prime}$ and $a$ paths in Figure 5 ). The analysis used PROCESS for SPSS (Model 8, Hayes, 2013). ${ }^{13}$

Affect and inferred speaker positivity both significantly predicted participants' attitudes in the food and fish farm scenarios ( $b$ paths in Figure 5), affect: $\beta_{\text {food }}=0.53, p<.001, \beta_{\text {fish }}=0.43, p<.001$; speaker positivity: $\beta_{\text {food }}=0.24, p<.001, \beta_{\text {fish }}=0.31, p<.001$. After accounting for affect and inferred speaker positivity, the direct moderated framing effect on attitude was still consistently significant, but reduced, $\beta_{\text {food }}=0.18, p<.001, \beta_{\text {fish }}=0.15, p<.001$. The indirect framing effects on attitudes (conditional on quantifier magnitude) showed that affect and inferred speaker positivity were statistically significant mediators in the two scenarios for both the small and large quantifiers: for the food scenario, affect: $b_{\text {small-quantifiers }}=-0.15,95 \%$ $\mathrm{Cl}[-0.25,-0.06], b_{\text {large-quantifiers }}=0.48,95 \% \mathrm{Cl}[0.36,0.61]$, speaker

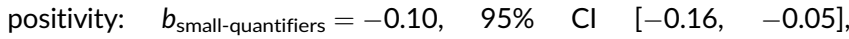
$b_{\text {large-quantifiers }}=0.21,95 \% \mathrm{Cl}[0.14,0.29]$; for the fish farm scenario, affect: $\quad b_{\text {small-quantifiers }}=-0.08, \quad 95 \% \quad \mathrm{Cl} \quad[-0.15, \quad-0.004]$, $b_{\text {large-quantifiers }}=0.51,95 \% \mathrm{Cl}[0.40,0.65]$, speaker positivity: $b_{\text {small-quantifiers }}=-0.10,95 \% \mathrm{Cl}[-0.16,-0.04], b_{\text {large-quantifiers }}=0.32$, $95 \% \mathrm{Cl}[0.22,0.43]$. This indicated that participants' affective associations with the frame and inferences about the speaker's positivity both partly explained differences in attitudes between the frames. A test of how quantifier magnitude moderated this mediation (i.e., the difference between conditional indirect effects) showed that this mediating role was greater for the large than the small quantifiers, affect: $b_{\text {food }}=0.63,95 \% \mathrm{Cl}[0.47,0.79], b_{\text {fish }}=0.59,95 \% \mathrm{Cl}[0.45$, 0.75]; speaker positivity: $b_{\text {food }}=0.31,95 \% \mathrm{Cl} \quad[0.21,0.43]$, $b_{\text {fish }}=0.42,95 \% \mathrm{Cl}[0.29,0.56]$.

Thus, overall, Experiment 4 supported our hypotheses that the direction of the framing effect reversed between small and large quantifiers and that affect and inferred speaker positivity mediated the framing effect. The evidence was consistent across two scenarios with different synonym pairs. However, we did not find the expected greater framing effect for verbal than numerical quantifiers.

\section{6 | GENERAL DISCUSSION}

In five pre-registered experiments, we found three main findings. First, we consistently replicated a framing effect for the synonyms "energy" and "calories." We showed that it extended to another synonym pair ("utilized" vs. "depleted"), though not the pair "dismissed" versus "fired." Second, we found that verbal quantifiers did not trigger larger framing effects than numerical quantifiers. Third, we found that the magnitude of quantifiers moderated the direction of the framing effect, producing framing effects opposite in direction to the valence of the independent attribute. Affect and inferred speaker positivity 
FIGURE 6 Participants' attitudes (1: not at all favorable, 7: very favorable) toward a food (top panel), fish farm (middle panel), and company (bottom panel) described with positive versus negative synonymous attributes (green circle vs. red square) in Experiment 4 [Colour figure can be viewed at wileyonlinelibrary.com]
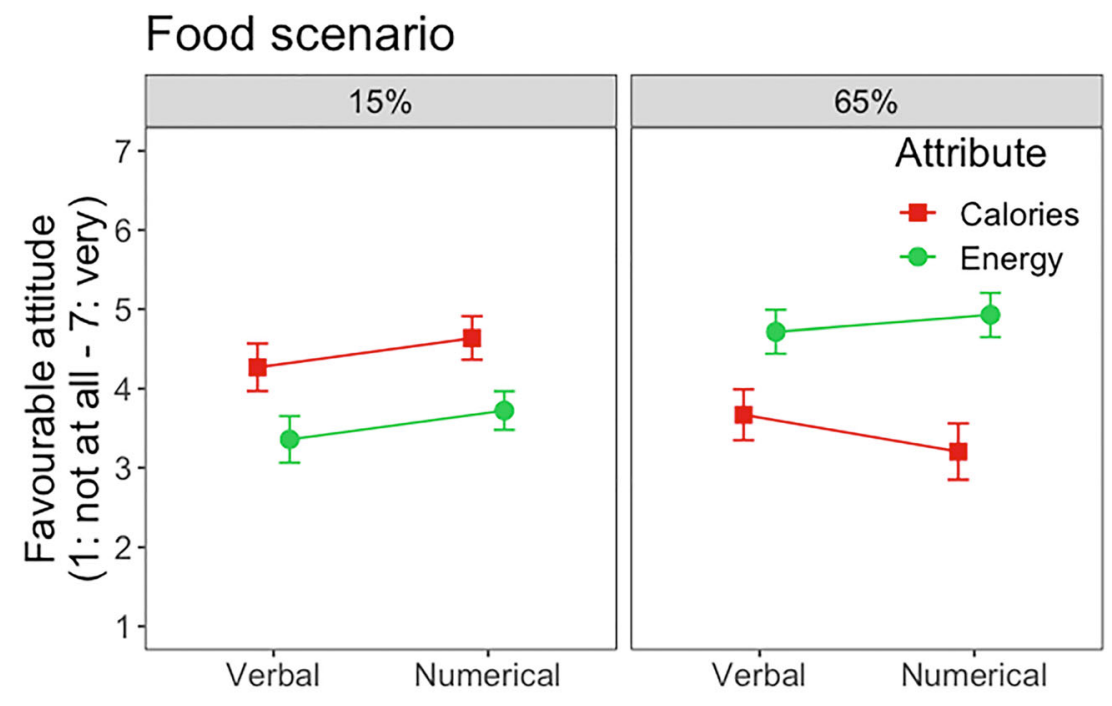

Fish farm scenario

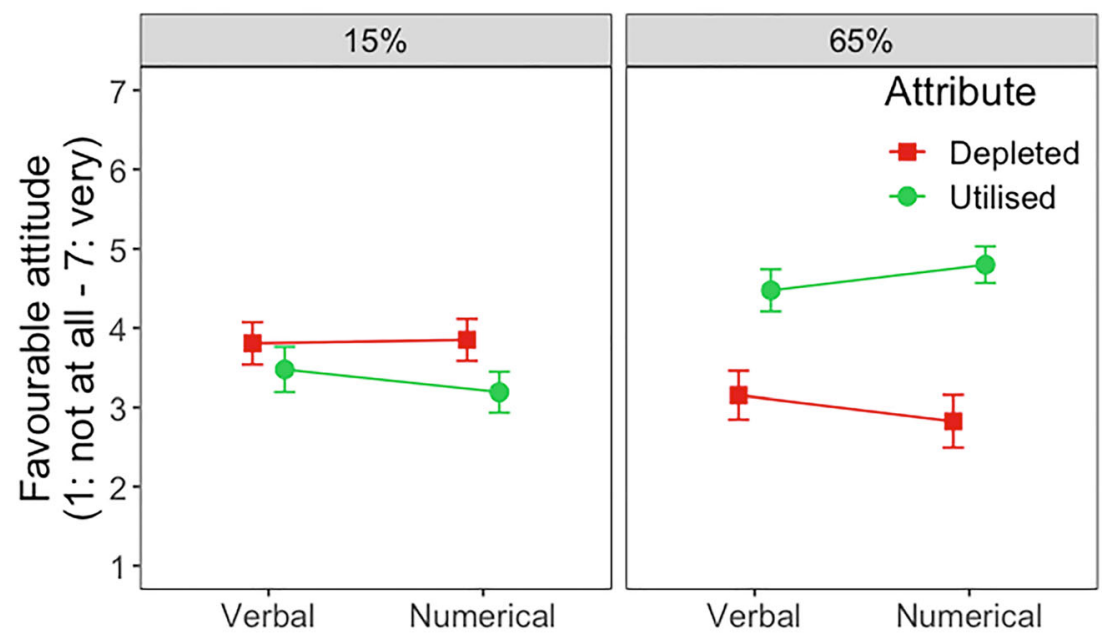

\section{Business scenario}

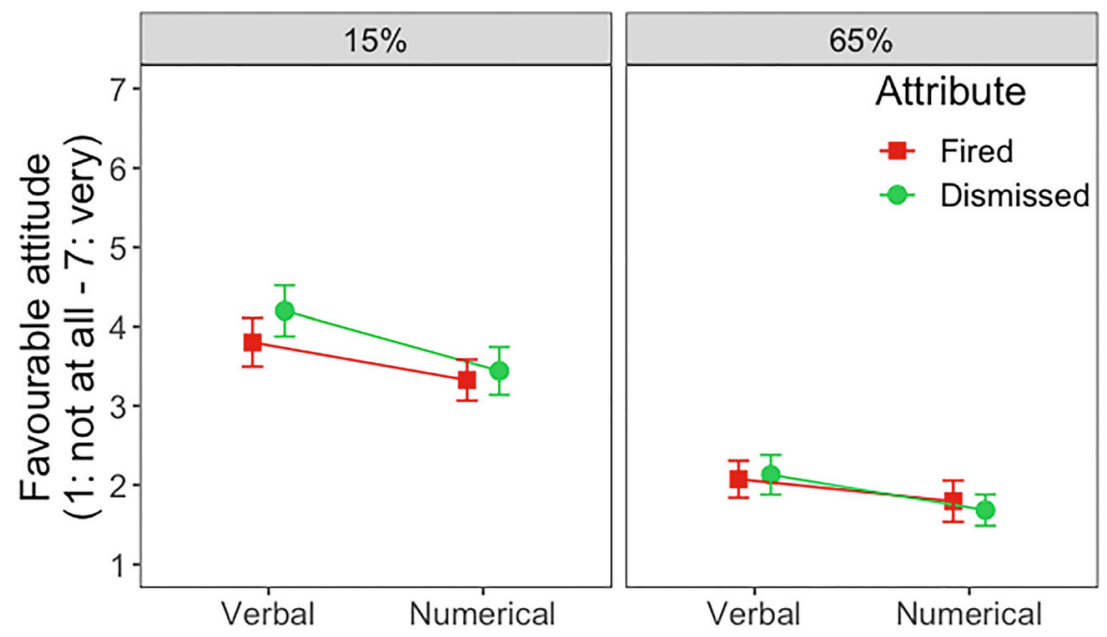

mediated the framing effect more for large quantifiers than small ones, highlighting that the quantifier makes an important contribution to the framing effect and the mechanisms behind it. Here, we discuss these findings in terms of their implications for psychological mechanisms behind framing, and considerations for future framing research.

\subsection{Framing effects with attribute synonyms}

Our experiments differed from typical attribute framing studies in that we did not use numerical complements and antonyms. We departed from the usual approach as this allowed us to test the effect of 
quantifier magnitude orthogonally to that of attribute valence. Our approach using synonyms that differed in valence was atypical, but not without precedent: synonyms were used in studies classified under goal framing (e.g., Epley et al., 2006) and attribute framing (e.g., Hardisty et al., 2010). Given our departure from the typical attribute research design, it is important to state the implications of our findings for the attribute framing literature as well as for other forms of framing effect such as goal framing.

Our synonyms depicted the same proportion of the same attribute in both frames. For example, we depicted the same proportion of fish harvested as either $15 \%$ utilization or $15 \%$ depletion. This is in contrast to the traditional attribute frame, which might depict the scenario as $15 \%$ depletion versus $85 \%$ conservation. These scenarios lead to the same proportions as in all of them, $15 \%$ of fish are gone and $85 \%$ remain. However, psychologically, the frames are perceived differently, producing the framing effect. We found a robust effect with two pairs of synonyms ( $d=0.3-0.8$ ), comparable with the antonym frames in the literature. The last pair, which had the smallest valence difference between the less negative "dismissed" and the more negative "fired," did not produce a framing effect. This suggests that synonyms need to show a sufficient valence difference, enough to distinguish the positive and negative frames. This may apply as well to antonym frames, where certain scenarios that are more clearly positive or negative find smaller or no effects (e.g., Gamliel \& Kreiner, 2019; Liu et al., 2020).

One may argue, however, that although the terms "energy" and "calories" describe an equivalent dietary contribution from the food, the frames do not convey the same meaning to the recipient. People may infer additional information from a speaker's choice of frame, for example, a glass described as half-full is believed to mean that it was empty before (Sher \& McKenzie, 2008), or 25\% fat may be inferred to be at least that much fat (as opposed to exactly so; Mandel, 2014). As a result, antonym frames would not be informationally equivalent because one can infer there is more fat (or water) in the negative frame and less in the positive. With synonyms, because the quantities in both frames are the same, these inferences should act in the same direction: the food has at least $15 \%$ of the calories (or at least $15 \%$ of the energy) you need. However, the synonyms may result in informational non-equivalence through other reasoning about the speaker's choice of frame. One can infer that a speaker used a positive descriptor because they recommend a certain course of action (Hilton, 2008; van Buiten \& Keren, 2009)-thus, energy provided is meant to be consumed, whereas calories provided are meant to be avoided. These inferences about what a speaker might recommend overlap with the conceptual criteria for goal framing, which has a focus on persuading individuals to support or adopt behaviors (Levin et al., 1998). While our experiments do not strictly align with goal framing in terms of what is framed and the target response, the two types of framing often overlap and are not exclusive. An information leakage perspective of framing effects with synonym frames could thus extend to goal framing, where two goal frames have different meanings for individuals because they reflect a speaker's recommendations. Considering how attribute and goal frames are constructed-using synonyms or antonyms-could provide more insight into the mechanisms shared by the two types of framing, and help explain studies with overlapping framing characteristics (e.g., Hardisty et al., 2010; Welkenhuysen et al., 2001).

\subsection{Quantifier characteristics and the framing effect}

Quantifiers play an important role in modifying one's perception of an attribute (Kiss \& Pafel, 2017). Using synonyms of relative positive or negative valence to maintain the same quantifier across frames, we found that the magnitude of quantifiers consistently interacted with the synonym's valence. This is consistent with other research where people were sensitive to whether a scenario on the whole was positive or negative, rather than just the attribute (e.g., people evaluated "65\% didn't fail" as better than "35\% didn't pass"; Kreiner \& Gamliel, 2019). Our experiments showed there was a reversal in judgements of the negative synonym when it had a small versus a large (or medium) quantifier. For example, we observed that judgements of calories tended to shift more depending on whether there were large or small amounts. When assessed on its own, the term "calories" received affect judgements around the center of the scale, so it was actually the less valenced term of the pair, but it was more negative than energy. It may be that negatively valenced terms are more sensitive to modification by quantifier magnitude-which could also explain why we did not find an effect with the fired versus dismissed synonyms, both of which are negative.

Compared with synonym attribute frames, research using antonym frames did not find consistent moderating effects of quantifier magnitude. Some found differences in the framing effect size (Gamliel \& Kreiner, 2019; Liu et al., 2020; Sanford et al., 2002); others did not (Jin et al., 2017; Kim et al., 2014; Saad \& Gill, 2014). Past studies often expected that a frame's valence would match the attribute's valence (e.g., any quantity of fat is more negatively valenced than complementary percentage of "lean"). However, we provided here evidence that with some combinations of quantities, the smaller quantity could reverse the frame's valence, thereby reducing, or possibly even cancelling, the difference in valence perception. For example, a negative frame of $5 \%$ fat is in fact positive-then raising the question: is it less positive than a $95 \%$ lean frame? If it is not, this could explain why the framing effect was smaller or disappeared for more extreme antonym frame combinations (Gamliel \& Kreiner, 2019; Liu et al., 2020), while studies that use more moderate combinations (e.g., $40 \%$ vs. $60 \%$ ) might not reflect an impact of the quantifier. Our findings highlight the need to check how the valence of the quantified attribute compares with the valence of the descriptor alone. This is important not just to attribute framing, but other framing types (e.g., goal framing) that may use quantifiers in the frame.

Our experiments also found that quantifier magnitude affected the extent to which affect and inferred speaker positivity explained the framing effect. Both the mediators operated in parallel, but mediation effects were greater for the large quantifiers, especially when 
mediated by affect. From this, we suggest that quantifier characteristics could also moderate the mechanisms by which people reach a judgment. For instance, affect more consistently predicted judgements for large than small quantifiers (in Experiments 1, 2a, 3, and 4). However, inferred speaker positivity consistently predicted judgements for both quantifier magnitudes (Experiments 2b, 3, and 4). This could indicate that although both factors contribute to people's judgements, people make more affective judgements with large than small quantifiers. These effects are consistent with both affect encoding and pragmatic explanations. With large quantifiers, a valenceconsistent shift in attitudes could be more prevalent as the affect associated with the attribute matches the affect for the entire quantified frame. People can also integrate pragmatic inferences about how quantities are usually phrased: in terms of how much there is rather than how little (Clark \& Clark, 1977). Thus small quantifiers act as a pragmatic marker for people to consider other aspects of the information, such as what the speaker might believe. The affective and pragmatic accounts may also relate to each other: if people perceive more positivity from a speaker, that could contribute to positive feelings about the target (Hilton, 2008; Hilton et al., 2005). Conversely, one might also infer that the positive affect they associate with the quantified frame is why speakers used positively valenced wording to describe the scenario. We do not know yet how the processes might interact, but having determined their contributory roles, we propose that future research examines the interplay of the two. Because our studies relied on mediation analyses, an important limitation is the reliance on correlations between dependent variables (affect, inference, and judgements) that cannot determine whether these variables have a causal effect on any of the others. One way to disentangle this in future work may be to manipulate each variable (e.g., the need to infer speaker positivity) by presenting participants with the speaker's actual opinions, and testing how this affects subsequent judgment.

A hypothesis we did not find support for was that larger framing effects would be found when words were used instead of numbers. We only found this in one study (2a), but we also found the opposite in another study (4), where the framing effect was greater for the numerical than verbal quantifiers, and there were no significant moderation effects in the other studies. Our results suggest there is not a difference in framing effect size between verbal and numerical quantifiers, similar to recent work with typical antonym frames by Gamliel and Kreiner (2019) and Liu et al. (2020)-but contrasting with findings of Welkenhuysen et al. (2001). Verbal quantifiers may not be processed more intuitively than numerical ones, at least not to the extent that it would magnify the framing effect.

In our mediation tests, we also found that the quantifier format affected neither participants' affect for the attribute frame nor what they inferred about speaker positivity, meaning quantifier format failed to magnify the affect or pragmatic signal as we had predicted. We had expected that verbal quantifiers would magnify these signals based on the evidence that verbal quantifiers produce more deviation from normative judgment (Windschitl \& Wells, 1996), increase attention on the context (Moxey, 2017), and possess more pragmatic signaling value (Teigen \& Brun, 1995, 2000). A reason why our findings were not as expected may be that many of these studies investigated a specific type of verbal quantifier: probabilities (e.g., pragmatic signaling: Teigen \& Brun, 1995, 2000; intuitive judgements: Windschitl \& Wells, 1996)-which suggests that verbal probabilities differ from other verbal quantifiers. Supporting this difference, recent evidence indicates that proportional verbal quantifiers, as used in our study, are similar to numerical quantifiers in what pragmatic focus they place on attributes in a frame (Liu et al., 2020). Another explanation to consider relates to the overlap between attribute and goal framing using antonyms or synonyms. Welkenhuysen et al.'s (2001) study with antonyms ( $25 \%$ chance of disease vs. $75 \%$ chance of no disease), which found a greater effect with verbal quantifiers, also targeted participants' support for a medical procedure. Their framing scenario thus overlaps with goal framing, and so it could be possible that quantifier format affects goal framing mechanisms rather than attribute framing ones.

\section{3 | Limitations and future directions}

Our five experiments showed that synonyms with different valence produce framing effects comparable with attribute framing with complementary antonyms, and the quantifier (but not its format) modified the frame's valence to produce a framing effect different in direction for small versus large quantifiers. The quantifier's magnitude also determined participants' affect and inferred speaker positivity for the frame, both of which contributed to judgment differences. These findings suggest that first, it is important to check how quantifier magnitude modifies the valence of the overall phrase, as this could affect framing effects even for complementary antonyms. Second, existing accounts and evidence for framing effects could overlap and operate in tandem, so integrating different accounts and typologies could provide a more nuanced view of the mechanisms behind attribute framing.

A limitation of our work is that we did not test more quantifier magnitudes in steadily increasing intervals, because this was not practical with verbal quantifiers, which have less precise increments (Budescu \& Wallsten, 1995). We therefore cannot identify if the effect would shrink and disappear before reversing in direction. Given that medium quantifiers had similar effects to large quantifiers (and also, complementary antonyms find an effect using 50\%, e.g., full vs. empty; Ingram et al., 2014), the reversal may only occur at a relatively small value. From a pragmatic perspective, one would likely draw more inferences as the informational quantity becomes more ambiguous (Grodner \& Sedivy, 2011; Liu et al., 2020). The less clearly positive or negative a set of frames, the more ambiguity there may be for the evaluation, which should produce larger framing effects. Testing for levels of ambiguity of different quantifier magnitudes would be another promising avenue to understand how the quantifier magnitude modifies frame valence.

We also see merit in examining whether other posited explanations for attribute framing, such as fuzzy-trace theory (Reyna \& Brainerd, 1991), can apply to synonym frames. Our findings do not suggest that participants' used the "gist" of the information (e.g., the 
food has some energy) instead of the verbatim representations (i.e., the exact information: $15 \%$ energy) in their judgment. Sensitivity to quantifier magnitude is posited to be evidence of using verbatim representations in antonym frames (Gamliel \& Kreiner, 2019), and our participants' evaluations consistently changed with the quantifier magnitude. However, because the quantities were identical in both frames, it is possible that people encode the modified valence in the gist of the information as well. We propose that future investigations target these different explanations to better understand how different mechanisms apply to different types of framing effects.

\section{ACKNOWLEDGMENTS}

This research was supported by EssexLab (seedcorn grant to D.L.H.), the Experimental Psychology Society (small grant to M.J.), and the U.K. Economics and Social Research Council (to D.L.H., grant number ES/V011901/1).

\section{CONFLICT OF INTEREST}

The authors report no conflicts of interest.

\section{ETHICAL APPROVAL}

Ethical approval for this study was obtained through the University of Essex ethical review committee.

\section{DATA AVAILABILITY STATEMENT}

Data and materials from the study are available on the Open Science Framework at https://osf.io/zkmy7.

\section{ORCID}

Dawn L. Holford (iD) https://orcid.org/0000-0002-6392-3991

Marie Juanchich (D) https://orcid.org/0000-0003-0241-9529

Miroslav Sirota (D) https://orcid.org/0000-0003-2117-9532

\section{ENDNOTES}

1 Using the classic attribute framing design of complementary antonyms, only one quantity can be the same in both frames: $50 \%$. One would not be able to effectively determine how increasing or decreasing the quantifier magnitude affects the overall valence, because increasing the positive attribute to $60 \%$ means decreasing the negative attribute to $40 \%$.

2 While this study is classified in the literature as attribute framing, we agree with a reviewer who pointed out that it shares characteristics of goal framing.

3 The experiment pre-registration can be found at this link: https://osf. io/ncq3m/.

${ }^{4}$ Because PROCESS does not provide replicable syntax, we replicated the individual mediation paths in Figure 2 in $\mathrm{R}$ and provide this code on the OSF (https://osf.io/wqyf3/).

5 The experiment pre-registration can be found at the following links: https://osf.io/ds5zp/ (2a) and https://osf.io/pvfm2/ (2b).

6 The average numerical translations were similar to the ones used in Experiment 1 (low: $M=19.47 \%, S D=21.20$; high: $M=66.63 \%$, $S D=23.07)$. Translations of energy were not significantly different to those of calories, low: $t(620)=-0.97, p=.333$, high: $t$ $(1034.5)=0.35, p=.726$.
${ }^{7}$ We did not produce a framing effect for the willingness-to-pay measure, perhaps because consumers do not necessarily prefer buying healthier products (Raghunathan et al., 2006). This highlights the need for dependent measures to bear sufficient relation to the framing task at hand (e.g., energy/calories are important to determining if a food is healthy; Graham \& Jeffery, 2011, but other elements affect the determination of price; Talati et al., 2017).

8 The experiment pre-registration can be found at the following link: https://osf.io/6vw3g/.

9 Participants did not translate low \% and high \% significantly differently for energy and calories, low: $t(389)=-1.23, p=.220$; high: $t$ $(402)=-1.41, p=.159$. The average numerical translations were $14.74 \%(S D=13.07)$ for low and $68.15 \%(S D=21.44)$ for high.

${ }^{10}$ We had planned a moderated mediation model (PROCESS Model 8) conditional on this assumption. Since the assumption was not met, we carried out the plan for a model without mediators and do not report a moderated model. However, we include coefficients for the moderated model as supporting information.

11 The experiment pre-registration can be found at the following link: https://osf.io/4gh8n/.

12 The pre-test also tested the valence differences of five complementary attribute pairs previously published in traditional attribute framing tasks. Four of these had effect sizes between $d=1.27$ (lean vs. fat) and $d=5.04$ (satisfied vs. dissatisfied). One previously used (successful) complementary attribute pair had a non-significant valence difference ( $d=0.20$ : wool vs. artificial fiber).

${ }^{13}$ We had also pre-registered as an alternative model a moderated mediation analysis that included quantifier format. However, this model did not find that quantifier format played a moderating role $\left(\beta_{\text {food }}=0.01\right.$, $p=.800, \beta_{\mathrm{fish}}=-0.02, p=329$ ). It also did not explain more variance than the analysis reported here (both $R^{2}=0.56$ ).

\section{REFERENCES}

Bleich, S. N., \& Pollack, K. M. (2010). The publics' understanding of daily caloric recommendations and their perceptions of calorie posting in chain restaurants. BMC Public Health, 10, 121. https://doi.org/10. 1186/1471-2458-10-121

Bucher, T., Collins, C., Rollo, M. E., McCaffrey, T. A., De Vlieger, N., Van der Bend, D., Truby, H., \& Perez-Cueto, F. J. A. (2016). Nudging consumers towards healthier choices: A systematic review of positional influences on food choice. British Journal of Nutrition, 115(12), 2252-2263. https://doi.org/10.1017/S0007114516001653

Budescu, D. V., \& Wallsten, T. S. (1995). Processing linguistic probabilities: General principles and empirical evidence. Psychology of Learning and Motivation, 32, 275-318. https://doi.org/10.1016/S0079-7421(08) 60313-8

Clark, H. H., \& Clark, E. V. (1977). Psychology and language: An introduction to psycholinguistics. Harcourt Brace Jovanovich.

Dardis, F. E., \& Shen, F. (2008). The influence of evidence type and product involvement on message-framing effects in advertising. Journal of Consumer Behaviour: An International Research Review, 7(3), 222-238. https://doi.org/10.1002/cb.247

Donovan, R. J., \& Jalleh, G. (1999). Positively versus negatively framed product attributes: The influence of involvement. Psychology and Marketing, 16(7), 613-630. https://doi.org/10.1002/(SICI)1520-6793 (199910)16:7\%3c613::AID-MAR4\%3e3.0.CO;2-F

Epley, N., Mak, D., \& Idson, L. C. (2006). Bonus or rebate?: The impact of income framing on spending and saving. Journal of Behavioral Decision Making, 19, 213-227. https://doi.org/10.1002/bdm.519

Fritz, M. S., \& MacKinnon, D. P. (2007). Required sample size to detect the mediated effect. Psychological Science, 18(3), 233-239. https://doi. org/10.1111/j.1467-9280.2007.01882.x 
Gal, D., \& Rucker, D. (2018). Loss aversion, intellectual inertia, and a call for a more contrarian science: A reply to Simonson \& Kivetz and Higgins \& Liberman. Journal of Consumer Psychology, 28(3), 533-539. https://doi.org/10.1002/jcpy.1044

Gamliel, E. (2013). To end life or not to prolong life: The effect of message framing on attitudes toward euthanasia. Journal of Health Psychology, 18(5), 693-703. https://doi.org/10.1177/1359105312455078

Gamliel, E., \& Kreiner, H. (2019). Applying fuzzy-trace theory to attributeframing bias: Gist and verbatim representations of quantitative information. Journal of Experimental Psychology: Learning, Memory, and Cognition, 46, 497-506. https://doi.org/10.1037/xlm0000741

Gamliel, E., \& Peer, E. (2010). Attribute framing affects the perceived fairness of health care allocation principles. Judgment \& Decision Making, 5(1), 11-20.

Graham, D. J., \& Jeffery, R. W. (2011). Location, location, location: Eyetracking evidence that consumers preferentially view prominently positioned nutrition information. Journal of the American Dietetic Association, 111(11), 1704-1711. http://www.pubmedcentral.nih.gov/ articlerender.fcgi?artid=3267975\%26tool=pmcentrez\%26rendertype =abstract, https://doi.org/10.1016/j.jada.2011.08.005

Grodner, D., \& Sedivy, J. C. (2011). The effect of speaker-specific information on pragmatic inferences. In E. A. Gibson \& N. J. Pearlmutter (Eds.), The processing and acquisition of reference (pp. 239-271). MIT Press. https://doi.org/10.7551/mitpress/9780262015127.003.0010

Hardisty, D. J., Johnson, E. J., \& Weber, E. U. (2010). A dirty word or a dirty world? Attribute framing, political affiliation, and query theory. Psychological Science, 21(1), 86-92. https://doi.org/10.1177/ 0956797609355572

Hayes, A. F. (2013). Introduction to mediation, moderation, and conditional process analysis: A regression-based approach. In D. A. Kenny \& T. D. Little (Eds.), Methodology in the social sciences. The Guilford Press.

Hilton, D. J. (2008). Emotional tone and argumentation in risk communication. Judgment \& Decision Making, 3(1), 100-110.

Hilton, D. J., Villejoubert, G., \& Bonnefon, J.-F. (2005). How to do things with logical expressions: Creating collective value through coordinated reasoning. In Interaction studies: Social behaviour and communication in biological and artificial systems (vol. 6, issue 1, pp. 103-117). John Benjamins. https://doi.org/10.1075/is.6.1.08hil

Ingram, J., Hand, C. J., \& Moxey, L. M. (2014). Processing inferences drawn from the logically equivalent frames half full and half empty. Journal of Cognitive Psychology, 26(7), 799-817. https://doi.org/10.1080/ 20445911.2014.956747

Isaac, M. S., \& Poor, M. (2016). The sleeper framing effect: The influence of frame valence on immediate and retrospective judgments. Journal of Consumer Psychology, 26(1), 53-65. https://doi.org/10.1016/j.jcps. 2015.05.002

Janiszewski, C., Silk, T., \& Cooke, A. J. (2003). Different scales for different frames: The role of subjective scales and experience in explaining attribute-framing effects. Journal of Consumer Research, 30(3), 311325. https://doi.org/10.1086/378612

Jin, J., Zhang, W., \& Chen, M. (2017). How consumers are affected by product descriptions in online shopping: Event-related potentials evidence of the attribute framing effect. Neuroscience Research, 125, 21-28. https://doi.org/10.1016/j.neures.2017.07.006

Keren, G. (2011). On the definition and possible underpinnings of framing effects: A brief review and a critical evaluation. In G. Keren (Ed.), Perspectives on framing (pp. 3-33). Psychology Press. https://doi.org/10. 4324/9780203854167

Keren, G. B. (2007). Framing, intentions, and trust-choice incompatibility. Organizational Behavior \& Human Decision Processes, 103(2), 238-255. https://doi.org/10.1016/j.obhdp.2007.02.002

Kim, J., Kim, J. E., \& Marshall, R. (2014). Search for the underlying mechanism of framing effects in multi-alternative multi-attribute decision situations. Journal of Business Research, 67(3), 378-385. https://doi.org/ 10.1016/j.jbusres.2012.12.024
Kiss, K. É., \& Pafel, J. (2017). Quantifier scope ambiguities. In M. Everaert \& H. C. Riemsdijk (Eds.), The Wiley Blackwell companion to syntax (Second ed.). John Wiley \& Sons. https://doi.org/10.1002/9781118358733. wbsyncom005

Kreiner, H., \& Gamliel, E. (2019). "Alive" or "not dead": The contribution of descriptors to attribute-framing bias. Quarterly Journal of Experimental Psychology, 72(12), 2776-2787. https://doi.org/10.1177/ 1747021819862508

Krishnamurthy, P., Carter, P., \& Blair, E. (2001). Attribute framing and goal framing effects in health decisions. Organizational Behavior and Human Decision Processes, 85(2), 382-399. https://doi.org/10.1006/obhd. 2001.2962

Kuvaas, B., \& Selart, M. (2004). Effects of attribute framing on cognitive processing and evaluation. Organizational Behavior \& Human Decision Processes, 95, 198-207. https://doi.org/10.1016/j.obhdp.2004. 08.001

Leong, L. M., McKenzie, C. R. M., Sher, S., \& Müller-Trede, J. (2017). The role of inference in attribute framing effects. Journal of Behavioral Decision Making, 10, 21-32. https://doi.org/10.1002/bdm.2030

Levin, I. P. (1987). Associative effects of information framing. Bulletin of the Psychonomic Society, 25(2), 85-86. https://doi.org/10.3758/ BF03330291

Levin, I. P., \& Gaeth, G. J. (1988). How consumers are affected by the framing of attribute information before and after consuming the product. Journal of Consumer Research, 15(3), 374-378. https://doi.org/10. $1086 / 209174$

Levin, I. P., Schneider, S. L., \& Gaeth, G. J. (1998). All frames are not created equal: A typology and critical analysis of framing effects. Organizational Behavior and Human Decision Processes, 76(2), 149-188. https://doi.org/10.1006/obhd.1998.2804

Liu, D., Juanchich, M., \& Sirota, M. (2020). Focus to an attribute with verbal or numerical quantifiers affects the attribute framing effect. Acta Psychologica, 208, 103088. https://doi.org/10.1016/j.actpsy.2020. 103088

Liu, D., Juanchich, M., Sirota, M., \& Orbell, S. (2019). People overestimate verbal quantities of nutrients on nutrition labels. Food Quality and Preference, 78, 103739. https://doi.org/10.1016/j.foodqual.2019.103739

MacGregor, D. G., Slovic, P., Dreman, D., \& Berry, M. (2000). Imagery, affect, and financial judgment. Journal of Psychology and Financial Markets, 1(2), 104-110. https://doi.org/10.1207/S15327760JPFM0102_2

Mandel, D. R. (2014). Do framing effects reveal irrational choice? Journal of Experimental Psychology: General, 143(3), 1185-1198. https://doi. org/10.1037/a0034207

McKenzie, C. R., \& Nelson, J. D. (2003). What a speaker's choice of frame reveals: Reference points, frame selection, and framing effects. Psychonomic Bulletin \& Review, 10(3), 596-602. https://doi.org/10.3758/ BF03196520

Moxey, L. M. (2017). Processing quantified noun phrases with numbers versus verbal quantifiers. Discourse Processes, 55(2), 136-145. https:// doi.org/10.1080/0163853X.2017.1330042

Naughton, P., McCarthy, S. N., \& McCarthy, M. B. (2015). The creation of a healthy eating motivation score and its association with food choice and physical activity in a cross sectional sample of Irish adults. International Journal of Behavioral Nutrition and Physical Activity, 12(74), 1-10. https://doi.org/10.1186/s12966-015-0234-0

Peng, J., Jiang, Y., Miao, D., Li, R., \& Xiao, W. (2013). Framing effects in medical situations: Distinctions of attribute, goal and risky choice frames. Journal of International Medical Research, 41(3), 771-776. https://doi.org/10.1177/0300060513476593

Piñon, A., \& Gambara, H. (2005). A meta-analytic review of framming effect: Risky, attribute and goal framing. Psicothema, 17(2), 325-331.

Raghunathan, R., Naylor, R. W., \& Hoyer, W. D. (2006). The unhealthy = tasty intuition and its effects on taste inferences, enjoyment, and choice of food products. Journal of Marketing, 70(4), 170-184. https:// doi.org/10.1509/jmkg.70.4.170 
Reyna, V. F., \& Brainerd, C. J. (1991). Fuzzy-trace theory and framing effects in choice: Gist extraction, truncation, and conversion. Journal of Behavioral Decision Making, 4(4), 249-262. https://doi.org/10. 1002/bdm.3960040403

Saad, G., \& Gill, T. (2014). The framing effect when evaluating prospective mates: An adaptationist perspective. Evolution and Human Behavior, 35, 184-192. https://doi.org/10.1016/j.evolhumbehav.2014.01.002

Sanford, A. J., Fay, N., Stewart, A., \& Moxey, L. M. (2002). Perspective in statements of quantity, with implications for consumer psychology. Psychological Science, 13, 130-134. https://doi.org/10.1111/14679280.00424

Seta, J. J., McCormick, M., Gallagher, P., McElroy, T., \& Seta, C. E. (2010). Voice frequency impacts hemispheric processing of attribute frames. Journal of Experimental Social Psychology, 46, 1089-1092. https://doi. org/10.1016/j.jesp.2010.06.009

Sher, S., \& McKenzie, C. R. M. (2006). Information leakage from logically equivalent frames. Cognition, 101(3), 467-494. https://doi.org/10. 1016/j.cognition.2005.11.001

Sher, S., \& McKenzie, C. R. M. (2008). Framing effects and rationality. In N. Chater \& M. Oaksford (Eds.), The probabilistic mind: Prospects for Bayesian cognitive science (pp. 79-96). Oxford University Press. https://doi.org/10.1093/acprof:oso/9780199216093.003.0004

Steiger, A., \& Kühberger, A. (2018). A meta-analytic re-appraisal of the framing effect. Zeitschrift für Psychologie, 226, 45-55. https://doi.org/ 10.1027/2151-2604/a000321

Talati, Z., Norman, R., Pettigrew, S., Neal, B., Kelly, B., Dixon, H., Ball, K., Miller, C., \& Shilton, T. (2017). The impact of interpretive and reductive front-of-pack labels on food choice and willingness to pay. International Journal of Behavioral Nutrition and Physical Activity, 14(1), 171 https://doi.org/10.1186/s12966-017-0628-2

Teigen, K. H., \& Brun, W. (1995). Yes, but it is uncertain: Direction and communicative intention of verbal probabilistic terms. Acta Psychologica, 88(3), 233-258. https://doi.org/10.1016/0001-6918(93) E0071-9

Teigen, K. H., \& Brun, W. (2000). Ambiguous probabilities: When does $p=0.3$ reflect a possibility, and when does it express a doubt? Journal of Behavioral Decision Making, 13, 345-362. https://doi.org/10.1002/ 1099-0771(200007/09)13:3\%3c345::AID-BDM358\%3e3.0.CO;2-U
Teigen, K. H., Juanchich, M., \& Filkukova, P. (2014). Verbal probabilities: An alternative approach. Quarterly Journal of Experimental Psychology, 67(1), 124-146. https://doi.org/10.1080/17470218.2013. 793731

Tversky, A., \& Kahneman, D. (1986). Rational choice and the framing of decisions. Journal of Business Ethics, 59(4, pt 2), S251-S278.

van Buiten, M., \& Keren, G. (2009). Speakers' choice of frame in binary choice: Effects of recommendation mode and option attractiveness. Judgment \& Decision Making, 4(1), 51-63.

Watson, W. L., Chapman, K., King, L., Kelly, B., Hughes, C., Yu Louie, J. C., Crawford, J., \& Gill, T. P. (2013). How well do Australian shoppers understand energy terms on food labels? Public Health Nutrition, 16(3), 409-417. http://www.ncbi.nlm.nih.gov/pubmed/22464021, https:// doi.org/10.1017/S1368980012000900

Welkenhuysen, M., Evers-Kiebooms, G., \& d'Ydewalle, G. (2001). The language of uncertainty in genetic risk communication: Framing and verbal versus numerical information. Patient Education and Counseling, 43(2), 179-187. https://doi.org/10.1016/S0738-3991(00) 00161-0

Windschitl, P. D., \& Wells, G. L. (1996). Measuring psychological uncertainty: Verbal versus numeric methods. Journal of Experimental Psychology: Applied, 2(4), 343-364. https://doi.org/10.1037//1076-898X.2. 4.343

\section{SUPPORTING INFORMATION}

Additional supporting information may be found online in the Supporting Information section at the end of this article.

How to cite this article: Holford, D. L., Juanchich, M., \& Sirota, M. (2021). Characteristics of quantifiers moderate the framing effect. Journal of Behavioral Decision Making, 1-23. https://doi. org/10.1002/bdm.2251 


\section{APPENDIX A.}

TABLE A1 Effect of frame and quantifier format on affect and healthiness judgements in tests of moderated mediation for three quantifier magnitudes in Experiment 1

\begin{tabular}{|c|c|c|c|c|}
\hline & $\beta$ & $p$ & $b$ & $95 \% \mathrm{Cl}$ \\
\hline \multicolumn{5}{|l|}{ Effect on affect $\left(R^{2}=.22, p<.001\right)$} \\
\hline Frame (a path) & 0.47 & $<.001$ & 0.94 & $0.59,1.20$ \\
\hline \multicolumn{5}{|l|}{ Effect on healthiness } \\
\hline \multicolumn{5}{|l|}{ Small quantifiers $\left(R^{2}=.11, p<.001\right)$} \\
\hline \multicolumn{5}{|l|}{ Direct effects } \\
\hline Affect $\times$ quantifier format ( $b$ path) & 0.02 & .903 & 0.02 & $-0.30,0.34$ \\
\hline Frame $\times$ quantifier format ( $c^{\prime}$ path) & 0.15 & .067 & 0.58 & $-0.04,1.20$ \\
\hline \multicolumn{5}{|l|}{ Indirect effect (mediation by affect) } \\
\hline Verbal quantifiers & - & - & -0.27 & $-0.54,-0.02$ \\
\hline Numerical quantifiers & - & - & -0.25 & $-0.49,-0.05$ \\
\hline \multicolumn{5}{|l|}{ Medium quantifiers $\left(R^{2}=.15, p<.001\right)$} \\
\hline \multicolumn{5}{|l|}{ Direct effects } \\
\hline Affect $\times$ quantifier format ( $b$ path) & -0.02 & .897 & -0.02 & $-0.34,0.30$ \\
\hline Frame $\times$ quantifier format ( $c^{\prime}$ path) & 0.02 & .846 & 0.06 & $-0.55,0.67$ \\
\hline \multicolumn{5}{|l|}{ Indirect effect (mediation by affect) } \\
\hline Verbal quantifiers & - & - & 0.12 & $-0.07,0.34$ \\
\hline Numerical quantifiers & - & - & 0.10 & $-0.11,0.32$ \\
\hline \multicolumn{5}{|l|}{ Large quantifiers $\left(R^{2}=.29, p<.001\right)$} \\
\hline \multicolumn{5}{|l|}{ Direct effects } \\
\hline Affect $\times$ quantifier format & -0.14 & .201 & -0.19 & $-0.48,0.10$ \\
\hline Frame $\times$ quantifier format & -0.01 & .907 & -0.03 & $-0.59,0.53$ \\
\hline \multicolumn{5}{|l|}{ Indirect effect (mediation by affect) } \\
\hline Verbal quantifiers & - & - & 0.32 & $0.13,0.55$ \\
\hline Numerical quantifiers & - & - & 0.14 & $-0.04,0.32$ \\
\hline
\end{tabular}

Note: PROCESS Model 15 (Hayes, 2013) was used to generate unstandardized coefficients, 95\% bootstrapped confidence intervals (based on 5000 simulations), and $p$ values. Figure 2 illustrates the corresponding pathways for each of the effects in the model. The $a$ path is the direct effect of frame on affect; the $b$ path is the direct effect of affect on healthiness; the $c^{\prime}$ path is the direct effect of frame on healthiness after accounting for the mediated pathway. 


\begin{tabular}{|c|c|c|c|c|}
\hline & $\beta$ & $p$ & $b$ & $95 \% \mathrm{Cl}$ \\
\hline \multicolumn{5}{|l|}{ Effect on affect $\left(R^{2}=0.24, p<.001\right)$} \\
\hline Frame (a path) & 0.49 & $<.001$ & 0.97 & $0.78,1.16$ \\
\hline \multicolumn{5}{|l|}{ Effect on healthiness } \\
\hline \multicolumn{5}{|l|}{ Small quantifiers $\left(R^{2}=0.08, p<.001\right)$} \\
\hline \multicolumn{5}{|l|}{ Direct effects } \\
\hline Affect $\times$ quantifier format ( $b$ path) & 0.29 & .008 & 0.65 & $0.18,1.13$ \\
\hline Frame $\times$ quantifier format ( $c^{\prime}$ path) & 0.06 & .560 & 0.07 & $-0.17,0.31$ \\
\hline \multicolumn{5}{|l|}{ Indirect effect (mediation by affect) } \\
\hline Verbal quantifiers & - & - & -0.12 & $-0.31,0.06$ \\
\hline Numerical quantifiers & - & - & -0.06 & $-0.30,0.15$ \\
\hline \multicolumn{5}{|l|}{ Large quantifiers $\left(R^{2}=0.19, p<.001\right)$} \\
\hline \multicolumn{5}{|l|}{ Direct effects } \\
\hline Affect $\times$ quantifier format ( $b$ path) & 0.02 & .874 & 0.02 & $-0.21,0.24$ \\
\hline Frame $\times$ quantifier format ( $c^{\prime}$ path) & 0.01 & .898 & 0.03 & $-0.42,0.48$ \\
\hline \multicolumn{5}{|l|}{ Indirect effect (mediation by affect) } \\
\hline Verbal quantifiers & - & - & 0.31 & $0.15,0.48$ \\
\hline Numerical quantifiers & - & - & 0.32 & $0.15,0.53$ \\
\hline
\end{tabular}

TABLE A2 Effect of frame and quantifier format on affect and healthiness judgements in tests of moderated mediation for small and large quantifiers in Experiment 2a

Note: PROCESS Model 15 (Hayes, 2013) was used to generate unstandardized coefficients, 95\% bootstrapped confidence intervals (based on 5000 simulations), and $p$ values. Figure 2 illustrates the corresponding pathways for each of the effects in the models. The $a$ path is the direct effect of frame on affect; the $b$ path is the direct effect of affect on healthiness; the $c^{\prime}$ path is the direct effect of frame on healthiness after accounting for the mediated pathway. 
TABLE A3 Effect of frame and quantifier format on inferred speaker positivity and healthiness judgements in tests of moderated mediation for small and large quantifiers in Experiment $2 b$

\begin{tabular}{|c|c|c|c|c|}
\hline & $\beta$ & $p$ & $b$ & $95 \% \mathrm{Cl}$ \\
\hline \multicolumn{5}{|l|}{ Effect on inferred speaker positivity } \\
\hline \multicolumn{5}{|l|}{ Small quantifiers $\left(R^{2}=.13, p<.001\right)$} \\
\hline Frame $\times$ quantifier format (moderated $a$ path) & 0.17 & .068 & 0.40 & $-0.03,0.83$ \\
\hline \multicolumn{5}{|l|}{ Large quantifiers $\left(R^{2}=.13, p<.001\right)$} \\
\hline Frame $\times$ quantifier format (moderated $a$ path) & -0.14 & .132 & -0.33 & $-0.76,0.10$ \\
\hline \multicolumn{5}{|l|}{ Effect on healthiness } \\
\hline \multicolumn{5}{|l|}{ Small quantifiers $\left(R^{2}=.43, p<.001\right)$} \\
\hline \multicolumn{5}{|l|}{ Direct effects } \\
\hline Inferred speaker positivity ( $b$ path) & 0.58 & $<.001$ & 0.58 & $0.48,0.67$ \\
\hline Frame $\times$ quantifier format (moderated $c^{\prime}$ path) & 0.07 & .389 & 0.15 & $-0.20,0.51$ \\
\hline \multicolumn{5}{|l|}{ Indirect effect (mediation by inferred speaker positivity) } \\
\hline Verbal quantifiers & - & - & -0.51 & $-0.70,-0.33$ \\
\hline Numerical quantifiers & - & - & -0.28 & $-0.47,-0.10$ \\
\hline \multicolumn{5}{|l|}{ Large quantifiers $\left(R^{2}=.45, p<.001\right)$} \\
\hline \multicolumn{5}{|l|}{ Direct effects } \\
\hline Inferred speaker positivity (b path) & 0.59 & $<.001$ & 0.59 & $0.50,0.69$ \\
\hline Frame $\times$ quantifier format (moderated $c^{\prime}$ path) & 0.02 & .748 & 0.06 & $-0.29,0.40$ \\
\hline \multicolumn{5}{|c|}{ Indirect effect (mediation by inferred speaker positivity) } \\
\hline Verbal quantifiers & - & - & 0.50 & $0.32,0.70$ \\
\hline Numerical quantifiers & - & - & 0.31 & $0.10,0.52$ \\
\hline
\end{tabular}

Note: PROCESS Model 8 (Hayes, 2013) was used to generate unstandardized coefficients, 95\% bootstrapped confidence intervals (based on 5000 simulations), and $p$ values. Figure 4 illustrates the corresponding pathways for each of the effects in the model. The $a$ path is the direct effect of frame on inferred speaker positivity, moderated by quantifier format; the $b$ path is the direct effect of inferred speaker positivity on healthiness; the $c^{\prime}$ path is the direct effect of frame (moderated by quantifier format) on healthiness after accounting for the mediated pathway. 


\begin{tabular}{|c|c|c|c|c|}
\hline & $\beta$ & $p$ & $\boldsymbol{b}$ & $95 \% \mathrm{Cl}$ \\
\hline \multicolumn{5}{|l|}{ Effect of frame on affect ( $a$ path) } \\
\hline \multicolumn{5}{|l|}{ Scenario } \\
\hline Small quantifiers $\left(R^{2}=0.11, p<.001\right)$ & -0.34 & $<.001$ & -0.68 & $-0.86,-0.49$ \\
\hline Large quantifiers $\left(R^{2}=0.20, p<.001\right)$ & 0.44 & $<.001$ & 0.88 & $0.71,1.06$ \\
\hline \multicolumn{5}{|l|}{ Effect of frame on inferred speaker positivity (a path) } \\
\hline Small quantifiers $\left(R^{2}=0.14, p<.001\right)$ & -0.37 & $<.001$ & -0.75 & $-0.93,-0.57$ \\
\hline Large quantifiers $\left(R^{2}=0.17, p<.001\right)$ & 0.41 & $<.001$ & 0.83 & $0.65,1.00$ \\
\hline \multicolumn{5}{|l|}{ Effect on healthiness } \\
\hline \multicolumn{5}{|l|}{ Quantity: Small $\left(R^{2}=.53, p<.001\right)$} \\
\hline \multicolumn{5}{|l|}{ Direct effects } \\
\hline Frame ( $c^{\prime}$ path) & -0.10 & .005 & -0.21 & $-0.36,-0.07$ \\
\hline Affect ( $b$ path) & 0.45 & $<.001$ & 0.45 & $0.37,0.54$ \\
\hline Inferred speaker positivity ( $b$ path) & 0.30 & $<.001$ & 0.30 & $0.21,0.39$ \\
\hline \multicolumn{5}{|l|}{ Indirect effects (mediation) } \\
\hline Mediation by affect & - & - & -0.31 & $-0.42,-0.20$ \\
\hline Mediation by inferred speaker positivity & - & - & -0.22 & $-0.32,-0.14$ \\
\hline Total mediation effect & - & - & -0.53 & $-0.42,-0.21$ \\
\hline \multicolumn{5}{|l|}{ Quantity: Large $\left(R^{2}=.64, p<.001\right)$} \\
\hline \multicolumn{5}{|l|}{ Direct effects } \\
\hline Frame ( $c^{\prime}$ path) & 0.09 & .010 & 0.18 & $0.04,0.31$ \\
\hline Affect ( $b$ path) & 0.54 & $<.001$ & 0.54 & $0.47,0.62$ \\
\hline Inferred speaker positivity ( $b$ path) & 0.29 & $<.001$ & 0.29 & $0.21,0.36$ \\
\hline \multicolumn{5}{|l|}{ Indirect (mediation) effects } \\
\hline Mediation by affect & - & - & 0.48 & $0.35,0.62$ \\
\hline Mediation by inferred speaker positivity & - & - & 0.24 & $0.15,0.33$ \\
\hline Total mediation effect & - & - & 0.72 & $0.58,0.85$ \\
\hline
\end{tabular}

TAB LE A4 Effect of frame on affect, inferred speaker positivity, and healthiness judgements in tests of mediation for small and large quantifiers in Experiment 3

Note: PROCESS Model 8 (Hayes, 2013) was used to generate unstandardized coefficients, 95\% bootstrapped confidence intervals (based on 5000 simulations), and $p$ values. Figure 5 illustrates the corresponding pathways for each of the effects in the model. The $a$ path is the direct effect of frame on the respective mediators (1: affect, 2 : inferred speaker positivity); the $b$ path is the direct effect of each of the mediators on healthiness; the $c^{\prime}$ path is the direct effect of frame on healthiness after accounting for the mediated pathways. 
TABLE A5 Effect of frame and quantifier magnitude on affect, inferred speaker positivity, and favorable attitude in tests of moderated mediation on two scenarios in Experiment 4

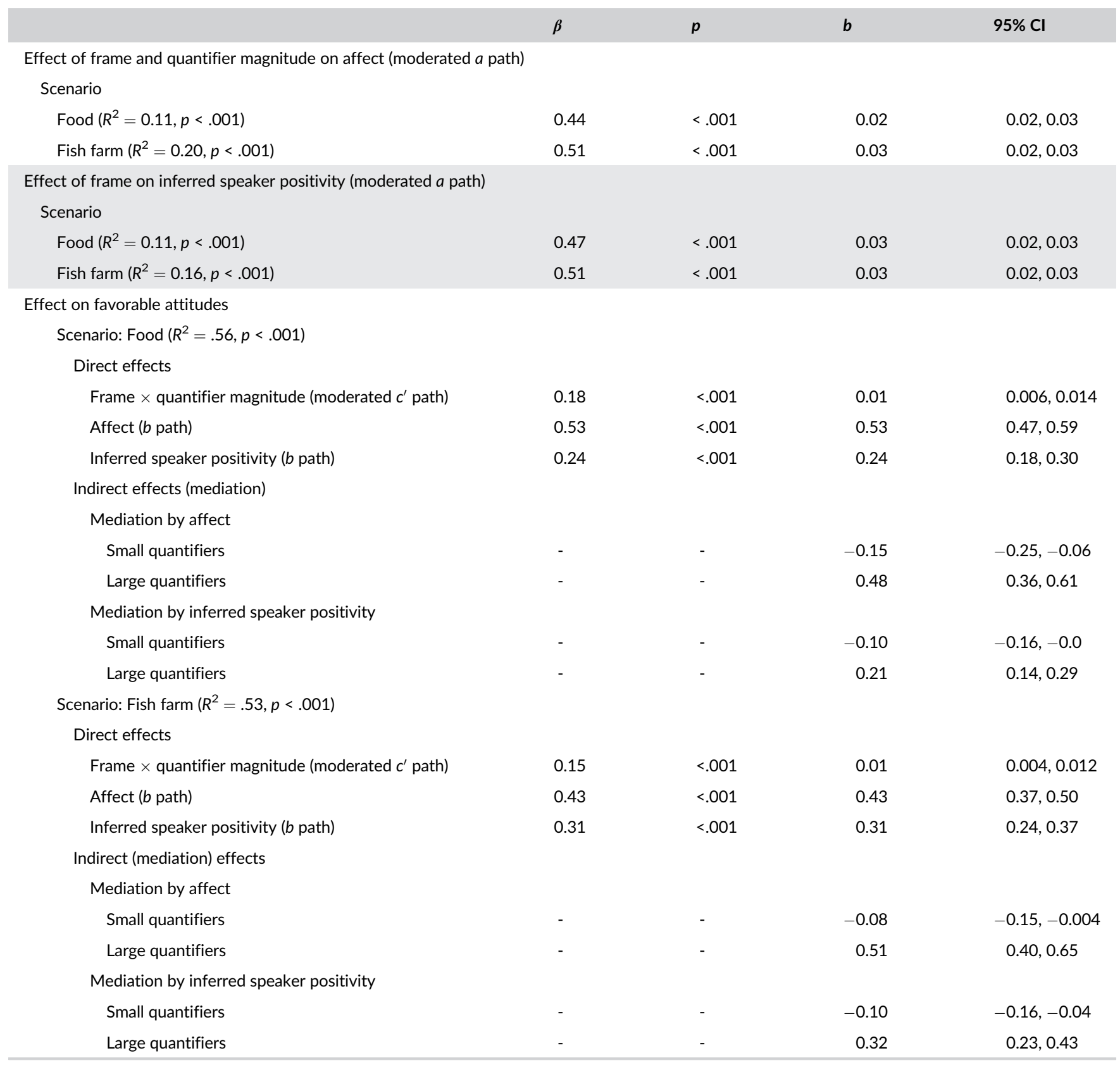

Note: PROCESS Model 8 (Hayes, 2013) was used to generate unstandardized coefficients, 95\% bootstrapped confidence intervals (based on 5000 simulations), and $p$ values. This model is similar to that illustrated in Figure 5, but with quantifier magnitude included as a moderator of the $a$ and $c^{\prime}$ paths. The $a$ path is the direct moderated effect of frame on the respective mediators (affect and inferred speaker positivity); the $b$ path is the direct effect of each of the mediators on favorable attitudes; the $c^{\prime}$ path is the direct moderated effect of frame on favorable attitudes after accounting for the mediated pathways. 